University of Rhode Island

DigitalCommons@URI

Open Access Dissertations

1977

\title{
LIFE SATISFACTION IN MOBILE AND NON-MOBILE ADULTS IN THE EARLY 30s
}

William Lawerence Wilson

University of Rhode Island

Follow this and additional works at: https://digitalcommons.uri.edu/oa_diss

\section{Recommended Citation}

Wilson, William Lawerence, "LIFE SATISFACTION IN MOBILE AND NON-MOBILE ADULTS IN THE EARLY 30s" (1977). Open Access Dissertations. Paper 1052.

https://digitalcommons.uri.edu/oa_diss/1052

This Dissertation is brought to you for free and open access by DigitalCommons@URI. It has been accepted for inclusion in Open Access Dissertations by an authorized administrator of DigitalCommons@URI. For more information, please contact digitalcommons-group@uri.edu. 
LIFE SATISEACTION IN

MOBILE AND NON-MOBILE

ADULTS IN THE EARLY $30 \mathrm{~S}$

By

William Lawrence Wilson

A DISSERTATION SUBMITTED IN PARTIAL FULFILLMENT OF THE REQUIREMENTS FOR THE DEGREE OF

DOCTOR OF PHILOSOPHY

IN

CLINICAL PSYCHOLOGY

UNIVERSITY OF RHODE ISLAND

1977 
Developmental theorists have suggested that adults progress through normal developmental stages. The time around age 30 has been identified as a period of turmoil followed by a stage of settling down and setting roots in the early $30 \mathrm{~s}$. This study was done to determine if forced mobility has a negative impact on couples in their early 30 s who are assumed to be facing a strong need to set roots. Subjects for this study consisted of two groups of 20 mobile and 20 non-mobile couples. The mobile population consisted of 20 couples in which the male was a military officer experiencing frequent forced occupational moves. The non-mobile population consisted of 20 civilian families in which the male worked for himself or in a small business. Non-mobility was defined as the family having lived in one location for five years and having the option to remain in that location an additional five years. Couples were matched on age and years of education of male member, number of children, and total family compensation. Subjects were voluntary participants contacted through friendships or organizational affiliations.

A two by two design was used comparing mobile and nonmobile males and females on life satistaction. Couples were compared on aspects of their lives that were taken with the family in moves and aspects that were left behind, and were also compared on a measure of self-actualization. Instruments used were Personal orientation Inventory, 
semantic differential, Life Evaluation Chart, Marriage Problem checklist, and a satisfaction scale.

All four groups reported satisfaction in all areas investigated and all four groups scored at a normal level of actualization. On the semantic differential non-mobile groups were significantly more satisfied than mobile groups with own friends, child's friends, and owning a house. Non-mobile groups scored significantly higher than mobile groups on Feeling Reactivity and Capacity for Intimate Contact on the POI. Marriage Problem Checklist indicated few problem areas, but most concern was found on issues relating to children and communication.

Consistent with developmental theorists, couples were found to experience satisfaction with their lives at this early 30 s stage. Non-mobile couples were busy establishing commitments to their occupation and family and establishing roots. Mobile couples were found to be establishing family commitments and commitments to their career and were able to maintain a level of satisfaction generally equal to the non-mobile couples.

The factor of mobility apparently did exert some influence on the level of satisfaction and self-actualization experienced by the mobile group, but it did not prove to be a very strong influence. 
I would like to express my sincere appreciation to my dissertation committee, Dr. James Prochaska, Chairman, Dr. Henry Biller, and Dr. Donald Spence, and to Drs. Wayne Velicer and Albert Lott for their assistance in the development and preparation of this study. Their guidance. support, and criticism were important and helpful throughout the process of this dissertation.

I also want to express appreciation and caring for Ed Hendren and Bill Cross who helped me to begin to see some of the issues involved in their own growth and mine. I appreciate the permission given by Family Life Publications. Inc. for the use of a modified form of their copyrighted Marriage Problem Checklist.

Finally, I express appreciation and love to Barbara who has been a partner in our life transitions as well as a partner in this study. 
Abstract ................ . ii Acknowledgments ............ . iv List of Tables .... . . . . . . vii List of Appendices . . . . . . . . . viii

I. INTRODUCTION . . . . . . . . . . . 1

Mobility, and Marital Satisfaction . - 11

Friendships . . . . . . . . . 19

Community . . . . . . . . . . 22

Career . . . . . . . . . 24

$\mathrm{Job} \cdot . \cdot \cdot \cdot \cdot \cdot \cdot \cdot \cdot 28$

Predicted Differences Between . . . 31

Mobile and Non-Mobile Couples

II. METHOD . . . . . . . . . . . 33

Subjects . . . . . . . . . 33

Procedure . . . . . . . . . 38

Instruments ........ . . 42

Analysis of Data . . . . . . 49

III. RESULTS - . . . . . . . . . 53

Sample Group Comparisons . . . 53

IV. DISCUSSION •. . . . . . . . . . 74

Marriage and Family . . . . . . 74

Friendships and Community . . . . 79

Career . . . . . . . . 85

Job •. •. • . . . . . . . 92

Overall Pattern of Response . . . 97

Self-Actualization . . . . . . 101 
TABLE OF CONTENTS (Cont'd.)

Chapter

Page

Sex Differences . . . . . . . 105

Limitations of the study . . . . 106

Clinical Implications . . . . . 110

REFERENCES •. . . . . . . . . 132 
1 Personal Orientation Scoring Categories

2 Demographic Mean and Standard Deviations for Sample Groups

3 Analysis of Variance for Demographic Data on Sample Groups

4 Mean and Standard Deviation Scores From the Personality Orientation Inventory for Mobile and Non-mobile Populations

5 Analysis of Variance summary, Personality Orientation Inventory

6 Mean and Standard Deviation Scores From Osgood Semantic Differential for Mobile and Non-mobile Populations

7 Analysis of Variance Summary, Osgood Semantic Differential

8 Ranking of Osgood Semantic Differential Items by Sample Groups, Highest Ranked Item to Lowest

9 Five Items of Highest Rated Concern by Sample Group on Marriage Problem Area Checklist

10 Mean and Standard Deviation Scores From Satisfaction Rating Scale for Mobile and Non-mobile Populations

11 Analysis of Variance Summary, Satisfaction Rating Scale 
Appendix

Page

A Request for Volunteers sheet . . . . .

B Modified Request for Volunteers . . . sheet

C Request for Volunteers Notice

Published in Ft. Ord Red Cross

Newsletter, "Variorum", 5 May 1976,

Vol. 1, No. 8

D Letter of Introduction to . . . . . .

Military Academy Graduates

E Structured Self-Report Battery . . . . Instruction sheet

F Personal Data collection sheet.....

G Male Interview Question Format . . . .

$\mathrm{H}$

Female Interview Question Format . . .

Semantic Differential

$\mathrm{J}$

Areas of Satisfaction Rating scale . . 
The study of development in the middle years of life is being increasingly recognized as an important area of investigation. Traditionally the study of development focused on the earliest years, childhood and adolescence, followed by a less than complete investigation of the last years of life dealing mainly with retirement and death. Researchers almost completely ignored the middle years, from young adulthood through middle age. In this omission, $70 \%$ of the human lifespan has received inadequate attention in the study of human development.

Fortunately, not all personologists have ignored the developmental issues of mid-life. First, a brief overview of the theoretical and empirical work of these investigators will be presented. Then a rationale will be provided to demonstrate how the present study can help advance our understanding of an important segment of mid-life.

Jung $(1933,1953)$ was one of the first personologists to propose that developmental stages occur throughout the Iife cycle. Jung postulated that there are three stages of consciousness. The first stage of life is a state of disorder and disruption ruled by instinct. The second stage is that of the developed ego-complex and is a more organized and directed state in which the person turns away from basic instincts or basic self, leading to the growth of consciousness. The development of direction by consciousness rather than instinct leads to internal 
conflict or problems.

Jung describes the second stage of life as the period of youth, extending from just after puberty to the middle of life or between the thirty-fifth and fortieth year. At this stage one is described as making certain presuppositions as one steps into adult life. These presuppositions are often false and may include exaggerated expectations, underestimations of difficulties, unjustified optimism in oneself and negative attitude toward the external world. Problems are encountered as the individual experiences a contrast between his subjective expectations and external facts. problems may also be due to inner, psychic disturbances attributable to such things as denial of sexual impulses or feelings of inferiority. Psychic disturbances may result from this denial of the true, instinctive self. Many dynamic theorists assume that this internal or intrapsychic conflict is of considerable importance in the development of personality. Resolution of these conflicts contributes to the development of self-esteem and an identity.

In the second stage of life the individual strives hardest for success and social approval in order to become a "social being." Part of becoming a social being includes entrenchment in one's own way of perceiving the world, including personal ideals and ways of conducting one's life. Entrenchment in one's unique approach to meeting the demands of society overlooks the essential fact that achievements rewarded by society are often pursued at the expense of one's own true personality. 
Jung indicates that the development of a feeling of moral resentment occurs at some point in a person's life. This resentment stems from a conflict with one's self which requires that the missing part of the psychological character be accounted for. It is Jung's view that when this realization is made, it is inevitable that the part of the psychological character which has been denied (the personal unconscious) will be brought into consciousness. This integration of instinctual and conscious aspects of the person is Jung's third life stage and begins with the awareness of one's divided state. The return to consciousness of the personal unconscious widens the scope of the individual's personality. This autonomous force within each person pushes towards wholeness, not perfection, and towards unique individualization or meaning in life.

Where Jung suggested three stages in the human life cycle, Erickson (1968) presented his famous eight stages of man. Each of Erickson's eight stages is concerned with a core conflict. Appropriate resolution of the conflict facilitates movement toward the next level or stage and towards a more mature level of functioning. Childhood ends and youth begins with Erickson's fifth stage of Identity versus Role Diffusion. This stage is concerned with the individual's ability to experience oneself as others appear to experience her. The individual compares this self perception with how they seem to be experienced by others. Resolution of differences between one's own feelings and the 
way others see her allows the individual to establish a sense of identity. A sense of identity allows the individual to focus on tangible goals, such as a career, and has been found by Erickson to be an important factor in the individual's ability to experience satisfying relationships with others. Mastery of the problem of identity allows the individual to begin to solve the problem of the sixth stage, Intimacy versus Isolation. Solution of the conflict of the sixth stage enables the individual to maintain intimate relationships with others and enables him to begin work towards the resolution of the next level's problem.

Erickson's seventh stage is Generativity versus stagnation and extends through the $40 \mathrm{~s}$ and 50s. In this seventh developmental stage the adult develops a new sense of creativity and paternal attitude in which a voluntary commitment is made to guide newer generations. All of the ego qualities developed through appropriate solutions to previous conflicts must be attained in order to become a mature and adequate adult. Erickson's proscription is that these qualities must be developed through socialization and adaptation of the organism.

Lowenthal, Thurner, Chiriboga et al. (1975) have been especially rigorous in delving into the specifics of various issues of adult development which reflect on the quality of life. These researchers have delineated four life transition points which appear especially important. These four events are situational, but the ease with which 
individuals pass through them depend on numerous psychological and cultural factors. The four groups facing critical stages in life delineated by Lowenthal et al. are: high school seniors (first job, college, marriage), newlyweds (parenthood), parents whose last child is leaving home (empty nest) and retirees. The research was conducted with 216 , mostly Caucasian men and women living within a large metropolitan city on the west coast. It is the authors' belief that they represent the mainstream of American life. Much of the findings of Lowenthal et al. bear on the quality of life and will be discussed later.

The feelings which an individual experiences in movement through the life experiences described by Lowenthal et al. have been investigated by Gould $(1972,1975)$. Gould has found the developmental sequence is towards greater tolerance of one's self and an appreciation of the complexity of the environment in which we exist.

The group of men studied by Gould (1972) in the 22- to 28-year old group (mid-20s) appear to feel autonomous and established. They are engaged in the work of being adults and believe that they are on their true course in life. The 22- to 28-year old's energy is spent mastering his activities, not questioning them. The 22- to 28-year old male feels that his sense of self is well-defined, although he may not be completely satisfied with it. The mid-20s male sees his spouse as someone who is not yet fully mature, but with whom a marital commitment can still be made. 
Extreme emotions are guarded against. The tone is toward modulated emotions in what he believes is the expected role of the "proper" adult.

Questioning of what life is all about begins when he reaches 29 to 34 years old (early 30s). He is weary of devoting himself to what he is supposed to be doing and is becoming aware of inner feelings which he does not fully understand. The 30-year old is weary of carrying out career and marriage roles in the prescribed manner. He just wants to be what he is. The young 30-year old sees his wife as preventing the new emergence by acting as witness to his former self and being unwilling to see the "new self." An existential questioning of his self and values in general has begun.

The 35- to 43-year old (late 30s) continues to question, but the questioning has been toned down towards quiet desperation. He feels that time is running out to change things. Work is often seen as the only source for compensation and a chance to make it before time is run out. The wife of the late 30-year old is seen by him as an individual in a similar position, and one who is also looking for support. An emphasis on the finitude of time is apparent to the couple and they have an equal eye to the past, present and future. The 30 s are characterized as shifting away from feelings of having unlimited individual power. The individual identifies himself more closely with an identity of the family. 
Gould's observations have been supported by the work of Levinson, Darrow, Klein, Levinson and McKee (1974), which is also concerned with the delineation of the aspects of male development throughout his life. The age span discussed by Levinson et al. extends from age 16 to older than 65. Levinson et al, are attempting to develop a hypothesis "concerning relatively universal, genotypic, age-linked, adult developmental periods within which (indıvidual) vàriations occur" (Levinson et al.. 19'14. p. 211). Levinson et al. see age-linked developmental periods that have origins in the makeup of numans and within societal forces which combine in such a manner that a normative developmental sequence is established. Linking the characteristics to age is important in demonstrating that development is continuing to occur throughout adulthood on some internal timetable basis in addition to an external cultural basis.

Levinson et al. have developed a view of the male's life as consisting of a number of apparently quiet and satisfying times. Quieter periods are separated by periods of developmental transitions or turning points between two periods of greater stability. The age 30 transition is one of these turning points and occurs between ages 28 and 32 . The period prior to the 30's transition is termed Getting Into The Adult World (GIAW) and begins in the early 20s, extending until 27 to 29. GIAW is a period of investigations of how it is to be an adult. Men enter this stage with a dream, typically set in an occupational 
context. The dream acts as a guidepost for the individual as he attempts to establish an ideal life structure. The male focuses primarily on the establishment of an occupation in GIAW. An occupational role model mentor is typically available to assist the man to begin to realize his dream.

The dream often has a part that includes a woman who assists the man to put the dream into reality. In a review of her own work and that of Levinson and of Gould, Sheehy (1974) indicates that an unspoken agreement is made whereby the wife will only peripherally involve herself in activities outside of the home. This interrupted growth for the woman may have complicating effects in the future. A time may come in her life when she expects to live out more aspects of her own dream or at least be appreciated by the male for her assistance in his dream. The husband may not have accounted for the needs of his wife for her fulfillment and may be unprepared to deal with her feelings when they come to the surface.

The 30's transition is a time when the man questions his commitments. Wide variations in the possibilities for resolving this transition are found. Resolution can result in a reaffirmation of the commitments earlier made or major modification in commitments may be accomplished. These major modifications can be a result of feeling constricted by the commitments or lack of congruence between the dream and perceived reality. Characteristics of the 
setting in which the individual has initially established himself may make major differences in the degree of conflict experienced by the individual, the duration of the transition, and the attitudes with which he approaches the next period, Settling Down (SD).

In settling down, the male makes deeper commitments and greater investments in his work and family. This is a period of establishing his niche in society and of setting his roots. Another aspect is the identification of a personal timetable for accomplishments he expects to reach, to include the age by which he expects to reach them.

Duration of transition periods may be drawn out. For example, those individuals who go directly into college or into the military may be delaying the onset of the first critical stage of adult life as described by Lowenthal et al. (1975) or strong movements into the adult world as described by Levinson et al. (1974). A modified version of the parental support, provided by the military or college rather than the family, may serve to retard the time of passage through the developmental sequence. Levinson et al. indicate the sequence of developmental events will eventually occur even in those individuals who remain in these institutional settings. Levinson et al. also insist that the sequence will occur in spite of apparent contentment at any given stage. A period of transition and disruption will follow each quiet period on a timetable of approximately every seven years. Only the specific concerns and views of 
one's self will vary. The relatively quiet periods before and after the transition would appear to be periods of satisfaction with the present way of living and experiencing life. The disruptions appear to involve dissatisfactions with previous ways of living and lack of meaningful relationships.

Developmental theorists indicate that the transition of this potentially crisis-filled stage of personal development--a conflict between the illusions of youth and realities of aging--is inevitable for all of us. A successful negotiation of this stage results in a development of one's sense of identity and a conviction of personal commitments. An environment not providing the opportunity for the individual to adequately meet the needs of the settling down period following the $30^{\prime} \mathrm{s}$ transition should result in decreased satisfaction.

Research has indicated that the male who negotiates the $30^{\prime}$ s transition with his family intact has renewed commitment to his family, interest in being "more of himself," improving his interaction with others and establishing "roots" into his community. The lifestyle of families not remaining in one location during this settling down period does not seem to provide the opportunity to establish roots and deep relationships with others. The issue of how situationally different lifestyles impact upon adult development, such as mobility impacting upon setting roots, has not yet been addressed by adult 
developmental theorists. This study is unique in its comparison of couples who are in the same stage of life but are in lifestyles that differ in the opportunity to remain in one location to establish roots. Specifically, this study focused upon the satisfaction reported by the $32-$ to 35-year old male and his wife in mobile and non-mobile lifestyles in the axeas of 1) marriage and family;

2) friendships; 3) community; 4) career: and 5) jobs. It was expected that forced mobility would have greatest negative impact on those areas of life that had to be left behind, such as friendships, aspects of community and job.

Mobility and Marital Satisfaction

One of the critical issues of the early 30 s is happiness with marriage. This period follows the tension-filled and maritally difficult $30^{\prime}$ s transition. The male who makes it through this transition with his family intact no longer sees his wife as a threat to his "real" identity. She is seen as an ally, as someone who is in a position in life similar to his own. He attempts to establish a calmer, if not closer relationship with her (Gould, 1972; Levinson et al., 1974). Although little developmental research has been accomplished with women at this stage, it appears that the wife is more accepting of the husband's refound identity and commitments. She also works at being more comfortable in the relationship.

There are at least six major variables that have been found related to marital satisfaction. These include: 
1) stage of life: 2) role adequacy; 3) focus of energy in the marriage; 4) household management; 5) sex differences: and 6 ) the presence of children.

The previous findings of marital satisfaction increasing after the turmoil of the 30's transition have been found with populations who generally have the choice to live in one area. It is uncertain if these findings of improved marital and family happiness occur for families experiencing forced mobility due to occupational requirements. In view of the fact that our society is apparently becoming increasingly more mobile, it is important to investigate more closely whether or not occupationally-forced mobility negatively affects marital and family satisfaction of the individuals at this stage of life. Since one of the critical psychological needs at this stage of life appears to be concerned with setting roots, forced mobility might be expected to have a profound negative impact on couples in their 30s.

One group in our society that has traditionally been very mobile is the military family. In this study couples from the military were used to represent the mobile group for a number of reasons. The military represents one occupation in which moves and uprooting are typical in the career. Many management positions in business also require frequent dislocations, but the military represents a career pattern in, which moves are expected and perhaps demanded if the officer is going to remain in the military. Given 
the regularity and frequency of moves in the military, it was assumed that any impact that mobility has on life satisfaction would be quite apparent in a military population.

The military population was also selected in part because of pragmatic considerations. Specifically, the investigator in this study is a career officer and was on active military duty and living on a military base. Since couples in this age group are difficult to engage in research, it was assumed that the investigator's contacts would help facilitate recruitment of subjects. Focusing on a mobile military group also provided the practical benefit to the investigator of learning first-hand how a sample of normal military couples deal with the stresses of separation and relocation.

If he marries early, the army officer begins his family under conditions of continual movement. His first year in the military usually includes a number of short assignments, providing schooling in basic military skills. These assignments can last from a few weeks to a few months. When possible, the wife accompanies her husband to these assignments; otherwise, she remains with the extended family. Movement to different locations continues throughout the military career with these mobile families considering themselves fortunate to stay in one location for two to three years. An average of one move per year is not uncommon. 
A career in the military requires frequent separation of the spouse. This may be a result of training duties in the field or at sea lasting from a few days to a few months, temporary duty (TDY) assignments to other locations lasting up to six months and long-term overseas assignments lasting up to 13 months.

A result of these separations is that additional responsibilities are placed upon the wife. These responsibilities include financial management as well as additional responsibilities in keeping the household going and in childrearing activities. This spouse often feels abandoned and resentful, being left to deal with the total household and child-rearing tasks. The children, feeling the absence of one parent, often require greater attention and frequently become "behavior" problems in school. Although the mobile wife has considerably more responsibilities than just housework, she probably does not have the time to accomplish all of her duties to satisfaction.

The mobile family has a larger number of potential problem areas than the non-mobile family. With every move the mobile family must find a place to live. Frequently this is only a temporary accommodation while waiting for a house to become available on the military installation. Communities must be located which provide adequate schools and activities for the children. Finding these communities in a new location and settling into them on a temporary basis takes considerable energy from the mobile couple. 
Energy may not be as readily available to the mobile couple as it is for non-mobile couples to deal with affectional issues of the early 30 s.

Due to an expenditure of energy in the stresses of moving we expected to find less satisfaction with marriage and family in the mobile population. The mobile group is faced with a double issue of transition into the 30 's crisis as well as making moves at the same time. The non-mobile population, on the other hand, can use its energies primarily to focus on particular stage issues rather than have many lifestyle issues with which to be concerned. Thus, we would expect that the mobile group that has diffused its energy into both stage and lifestyle changes would show more dissatisfaction.

Marital satisfaction generally decreases to a low point with the 28- to 32-year old stage, the 30's transition (Levinson et al., 1974). Pineo (1968) indicated that this disenchantment is inevitable. Individuals marry by personal choice and at a time when they are most likely to construe a high degree of fit between themselves and their partners. Changes in the environment and ways of interacting occur as time passes and are the main contributor to the disenchantment after five years of marriage. Although these changes do not necessitate that dissatisfaction increase with the disenchantment, empirical evidence indicates that it does. The disenchantment appeared to occur earlier for the man in Pineo's study than for the woman. 
A review of marital happiness by Hicks and Platt (1970) indicated that one of the more important predictors of happiness in a marriage is the perceived adequacy of marriage roles within the relationship. The husband and wife have expectations of their own behavior within the marriage as well as expectations for the behavior of their spouse. Satisfaction in marriage has a high positive relationship to the fit of these expectations to observed behavior (Ort, 1950; Hawkins \& Johnson, 1969). This relationship of satisfaction and behavior fitting marital roles begins early in the relationship (Lowenthal et al., 1975). The adequacy of the male role is more important than the female's role adequacy in predicting satisfaction (Hicks \& Platt, 1970).

A satisfied marriage includes a focusing of both partners on the marriage relationship (Gurin et al., 1960). However, in the 20 s the husband focuses on his instrumental tasks of establishing himself in an occupation and establishing financial security (Harry, 1976). The male's instrumental focus is especially a problem for the nonworking wife when she realizes that the communication, intimacy, and companionship that she values (Garai, 1970) is not what her husband values. The husband will not feel free to address the affectional issues until he feels more secure in his occupation and finances (Levinger, 1966; Fengler, 1973). One event that begins to force the husband's attention more toward the family is the arrival of children 
(Harry, 1976). The problem that exists with this redirection of the husband's attention is that it occurs under duress stemming from the wife's unhappiness and demands of the children.

There are other sources of dissatisfaction for the woman in marriage at this age. Bernard (1972) attributes the repetitious and boring nature of housework to dulling the housewife, convincing the wife that she is unable to deal with out-of-house demands as well. Within a few years of marriage, this housewife will be found to be in poorer psychological health than her unmarried sisters. Bernard reports that marriage appears to have the opposite effect on men. Men appear to psychologically benefit from marriage, whereas women appear to decline.

There is one glimmer of hope and source of satisfaction for the woman. If she remains married and her husband progresses in status or prestige in his occupation, this has been found to have a positive relationship to marital satisfaction (Blood \& Wolfe, 1960).

As for the married male, as he approaches the age of 30. Levinson (1974) and Gould (1972) report that his dissatisfaction with his previous way of living increases. He sees himself as living out an expected role rather than his own life. Wife, mentor and parents are blamed for the male's conflict. The 30-year old man typically sees family and career as situations in which he is stuck and living out expected roles. The man at 30 often feels unable to 
find expression for his true self.

In addition to what appears to be a "normal" progression towards dissatisfaction by the wife and uninvolvement by the husband, children add another important dimension to satisfaction in the marriage and family. The period of preschool and early school-aged children in the family has been termed the family cycle crunch or squeeze by wilensky (1961). Children place a demand on the occupationallyoriented male and upon the family finances that require attention. Harry (1976) indicates that the husband responds by redefining happiness. Rather than correlating satisfaction with extra-familial activities as he did prior to children, he now correlates his life satisfaction with activities within the family. Harry's data indicate a general drop in reported satisfaction level, even though satisfaction is now correlated within the family.

Although the marriage and family now receive a greater portion of the husband's concern, the woman does not experience increased satisfaction. In fact, the arrival of children places greater demands upon the time available to her and she typically experiences less satisfaction than before the children (Rollins \& Feldman, 1970). The level of satisfaction experienced by women reaches an all-time low with the arrival of children and will not climb back to a level equal to the earliest part of the marriage until the last child leaves home (Lowenthal et al.. 1975).

In summary, it can be seen that a number of factors bearing on marriage satisfaction come together in the early 
30s. At this age the family normally has children. The husband is able to gauge his probable success in his occupation (Gould, 1972; Levinson et al.. 1974; Sarason, 1975) and he is able to focus more of his attention on his relationship with his family and others. The family cycle crunch results in a demand that the husband focus on the marriage. Although the wife may not have been satisfied with her husband's marital role enactment, his roles prove to be predictable and his behavior now fits her modified expectations. At this point he desires to be his own man and not to be hemmed in by the family and marital demands. This results in considerable turmoil (Gould, 1972; Levinson et al., 1974).

\section{Friendships}

Friendships have been found to have considerable impact on reported life satisfaction.: Bradburn (1969) found that individuals who have the time and characteristics which involve them with other people experience happier Iives than their less socially-involved peers. This relationship of involvement and happiness is supported by Wilson's (1967) report that the most impressive single finding in the happiness research is a correlation of happiness and successful involvement with people. It does appear that the more involvement one has with others, the more satisfaction one experiences in life.

Friendships provide the opportunity for greater selfawareness of oneself. Jourard $(1964,1971)$ has indicated 
that successful involvement with other people provides the opportunity for greater awareness of the intrapersonal as well as interpersonal self. This awareness occurs through self-disclosure of oneself. Conditions for self-disclosure are partially provided by a trusting and accepting other person, a friend. This interaction is qualitatively unique compared to the more superficial interactions of daily living and results in considerable attachment to the friend.

The awareness we have of ourselves is frequently shaped by the social context in which we live. Jung (1933) indicates that people portray an image of themselves to others and society that has been learned and shaped through the reward and punishment of societal approval. This projected self often denies deeper awareness of ourselves.' Interaction with trusted and accepting other persons provides the opportunity for self-disclosure of these more private and personal aspects of ourself. Feedback from this other trusted person, a friend, allows for greater personal acceptance of the self-image and improved interaction of it into the projected self-image. Lowenthal et al. (1975) have found that a congruence of projected self-image and own self-image is positively related to satisfaction in life. The non-mobile civilian family, living in one community for a number of years and feeling that they can remain there for a number of years if they choose, have the opportunity to establish deep friendships. Normal community activities 
of the family and occupational relationships can develop over a number of years into deeper friendships conducive to self-awareness. As they meet other people, the nonmobile couple have the opportunity to pick and choose those individuals with whom they would like to establish deeper relationships.

The mobile lifestyle complicates the establishment of lasting deep relationships. By its very nature of mobility, this lifestyle results in frequently disrupted friendships. The mobile male and his wife typically socialize with other officers with whom he works and really breaking totally away from occupational issues is infrequent.

The situation for the mobile wife is more complicated. Physical separation from the extended family initially results in the army officer's non-working wife frequently establishing intense but short-lived friendships with other young officer's wives. Geographic dislocations result in the disruption of these friendships. Increasing reluctance to establish deep and confiding relationships often develops due to the upsetting experience of their frequent dissolution. As the military career progresses, the officer's wife finds greater comfort and security in the confines of the military community (Just, 1970), and she often commits herself to ascribed army wife roles (Dobrofsky \& Batterson, 1977; Ladycom, 1977), believing that it contributes to success in her husband's career. 
She often becomes involved in volunteer work and military community activities. She appears to have a number of friends, but few relationships of the nature that would provide the opportunity for greater self-awareness.

The wife's involvement in the community but lack of deep friendships result in competing factors for her satisfaction. Her structured role enactment and lack of opportunity for self-awareness would tend to operate against her satisfaction with herself. The enhancement of her selfesteem through needed contributions to the community and her husband's career operate in a direction of positive satisfaction (Bachman et al., 1967: Wilson, 1967; Robinson, 1969). It is probable that this mobile woman experiences a superficial level of satisfaction, but the lack of selfawareness, role enactment of army wife and lack of congruence in projected and own self-image result in a decrease in overall life satisfaction. She may experience this as a lack of fulfillment and is in a direction opposite of the developmental sequence that is occurring for the non-mobile woman at this time.

\section{Community}

The concept of community has important implications for the satisfaction experienced by a couple at the early 30's stage. Levinson et al. (1974) and Gould (1972) have indicated that the establishment of one's roots is a critical issue in the early 30s. This is a time when one desires to make commitments and establish oneself. These 
comitments extend to the occupation and to the family, but are also extended to the community in a desire to establish roots or a solid foundation. Neighborhoods are evaluated for quality of schooling, activities for the children and quality of friends their children might have. Location of a desirable community the couple can afford leads to a settling in. This settling in and commitment to the community is often reflected in the buying of a house and in extensive involvement in community activities.

The non-mobile lifestyle affords greater opportunity to set community roots. Living for years in the community provides the non-mobile couple with time to assess and look into those activities to which they would like to contribute time and effort. The non-mobile couple does not experience pressure to devote time to any particular activity except through their children's participation in some activities. When time permits, the non-mobile woman is free to become involved in activities of her choosing. The mobile officer family does not have the opportunity to establish community roots similar to those of the nonmobile family. By the time he reaches his early 30s, the army officer has accrued enough rank to receive a house on the military base. The house or quarters become taken for granted as part of what he expects from his career. A desire for a better living place may result in his looking for housing off-post, but this house is often rented or bought mainly for financial gain. Locating a house with 
these attitudes results in a temporary feeling to the living arrangement.

Community involvement for the mobile family is probably more limited than that of the non-mobile family. The army community is under the leadership of a post commander assigned to that position, so the mobile couple does not have the opportunity to affect community management. The mobile family is left to become involved in activities which are more oriented to seasonal activities that are temporary in nature, such as youth programs and wives' activities.

The army wife often experiences sources of dissatisfaction in her participation in community activities. These dissatisfactions result from perceived expectations and pressure that she should be involved in volunteer work and community activities in the proper enactment of her role as an army wife (Dobrofsky \& Batterson, 1977). Although these activities have been found to be satisfying activities for this early 30 s age group, the perceived pressure is dissruptive and results in the woman's not being sure if she is involved in the community because she wants to or because she has to in order to avoid hurting her husband's career.

\section{Career}

Although the placing of roots in a community and improving interpersonal relationships is a critical issue of the early 30s, occupational satisfaction continues to be an important factor in life satisfaction. Factors which bear on occupational satisfaction come from the long-range 
occupational goal, a sense of identity with the occupation and from the day-to-day activities that we call the job.

The concept of career in this study applies only to the men when their wives do not work outside of the house. Career is used in the sense that it is an occupation which requires specialized training and develops in a stepwise fashion. The non-working wife does not receive any specialized training to be a wife, mother, and housewife, and, in the sense used, does not have a career. Research (Dobrofsky \& Batterson, 1977; Blood \& Wolfe, 1960) indicates that the non-working wife does derive satisfaction from her husband's career when the career progresses well.

The career of the male in his early $30 \mathrm{~s}$ is often a source of satisfaction. A new commitment usually has been made to the career chosen in the 20 s or he has made a commitment in another direction (Gould, 1972; Levinson et al.. 1974). The source of satisfaction seems to be found in the commitment and the direction it provides. This commitment and goal-directedness provide an identity (Sarason, 1975) which has been found to be the most important factor in male happiness (Garai, 1970).

The roots and interpersonal commitments established by the non-mobile family in the early 30 s may make the pursuit of a career more difficult. Middle and upper management positions in a professional career often call for a stepwise progression through higher positions. Many professions do not provide the opportunity for this to 
occur in one location. Businesses are larger and more spread into other cities and states than ever. Decisions to pursue the career may require that the non-mobile family give up its non-mobility. An option to giving up the non-mobility is to change to another business firm offering a similar profession line. This would be advantageous if the new affiliation did not require movement for the next level of management, but allowed for a continuation of the career.

The mobile military family does not have as many options or control over the occupational situation as the non-mobile family. The military family does not control movements to other locations, staying at one job assigmment, or even the particular direction that the career might take. The military officer expects to stay in one location for a maximum of three years. He usually expects at least two different job assignments within this time. His career is designed to provide him with an alternation of schooling to learn skills, then assignments to utilize the learned skills. If he continues to demonstrate proficiency and ability in getting the job done, as seen on his periodic efficiency reports, he will progress in the career.

Progression is seen through rank attainment as well as nature of the job assignments. If his efficiency reports and military record indicate that he is not progressing satisfactorily, he may be eliminated from the service and his career terminated. The termination is in keeping with 
the concept that an officer should continue to progress in the career or be eliminated. Remaining at one level of career progression is not acceptable performance.

The army is divided into a number of specialty areas, such as personnel, intelligence, operations, and logistics. Military requirements call for a balance of officers assigned to these areas. Officers do provide input for their personal interests and preferences, but the final decision for which areas they will pursue and which military schools they will attend is determined by the military.

Mobility does not necessarily operate against military career satisfaction. The military family is mobile in pursuit of the career. Rapid mobility provides the opportunity to do more of the things the officer is expected to do towards his progression through the career. Opportunities for career advancement often occur with little notice and the officer is expected to take maximum advantage of these opportunities to further his career (Just, 1970). In this sense, mobility is a factor contributing to the satisfaction of the military officer. Mobility is an indication that his talents are in demand and that the military is pushing him through job experiences.

The developmental theorists have identified issues of the early 30 s which may result in less career satisfaction for the mobile male. Levinson et al. (1974) and Gould (1972) indicate that a need to set roots and to be one's own man free of any expectations but his own occur after the 30's 
transition. As discussed previously, a mobile lifestyle does not offer this opportunity in the traditional sense. A solution to this problem for the military officer may be for him to make a greater personal commitment to the career or to leave it to begin a new career.

Non-mobile and mobile wives may identify their career as mother or housewife and ascribe a level of satisfaction to it during this early $30^{\prime}$ s time period. In the sense that these women see taking care of and raising a family as their life's work, these roles may be identified by them as a career. We anticipate that there will be little distinction between the satisfaction mobile and non-mobile women experience with "career" and the next area that we call the job.

$\underline{\mathrm{Job}}$

Different factors bear on the satisfaction of the job than on career satisfaction. We use the term job to apply to the day-to-day occupational duties one accomplishes. Satisfaction with career differs from job satisfaction through its focus. Career satisfaction focuses upon a feeling of movement and direction towards a goal. The person believes achievement of this lifetime occupational goal will provide him with satisfaction (Garai, 1970). Job satisfaction has been identified by Herzberg (1966) as focusing upon the work environment including such factors as interpersonal relationships in the work setting and perceived value of the work. 
The non-mobile male appears to have more freedom in electing the setting in which he desires to work. More than one business has similar kinds of job offerings and the non-mobile male is free to interview in as many settings as he desires. If the working atmosphere becomes too distasteful, he may transfer to another firm. This is not to say that the non-mobile worker does not have considerable other factors bearing on a decision to leave one firm for another similar job position, but he does have alternatives not available to the mobile military officer.

The military officer sees his job as a step up the career ladder. The job is one step in which he must do well to progress upward. Switching firms to leave a distasteful job atmosphere is not possible since other firms do not offer a similar line of work. The interpersonal relationships are more formally structured in the military setting and are oriented towards task completion rather than towards self-awareness or growth (Just, 1970). The military officer learns to operate within fairly strict and formalized confines of interpersonal relationships at each job setting. The civilian counterpart experiences less structure and greater opportunity for self-expression.

The non-mobile worker is often in a position to have greater impact on his job setting than the mobile male, and this contributes to his satisfaction with his job. As he remains in one setting, the non-mobile male can influence changes in a direction in which he would like to see job 
enactment and setting progress. The non-mobile male frequently develops an investment in the job and wants to see it grow in a positive direction through his efforts. This personal involvement in the job contributes to a sense of satisfaction with it.

The mobile officer realizes that his improvements will typically be short-lived and his satisfaction in specific accomplishments of the job are transitory. Typical job assignments usually last for 18 months or less. The mobile male will frequently make his mark or individualize his job role and setting where he can influence it, but this is typically changed by the next officer assigned to the job. The positive aspects from the job may come more from a feeling of working towards a group goal with peers than from the setting. The structured nature of the interpersonal interactions interferes with these men discussing the positive interpersonal aspects of the military job. The transitory nature of the job experienced by the mobile male works against his satisfaction with the job. It was predicted that non-mobile males would experience greater job satisfaction than mobile males.

The non-mobile and mobile non-working wives in their early 30 s are still in the family cycle crunch (Wilensky, 1961), but are beginning to see some respite. The children still demand considerable time and attention from her, but as the children grow older they are able to assist these women with some of the household and younger child-watching tasks. Housework remains the big task for women of both 
groups. Repetitive and dulling by nature (Bernard, 1972), housework is experienced as a source of dissatisfaction for mobile and non-mobile women.

Predicted Differences Between Mobile and Non-Mobile Couples

Differences in life satisfaction between the mobile and non-mobile individuals were predicted to be greater in those areas of life in which mobility has the greatest impact upon developmental issues of the 30s. Obviously, mobility has been conceptualized as having greatest negative impact on the developmental needs of people in their 30 s to set roots. Mobile individuals are predicted, then, to report less satisfaction than non-mobile individuals in those areas of life satisfaction that are most uprooted by forced mobility. The specific areas of life that would be most affected are friends, children's friends, home, children's school, parents and job. Non-mobile couples were predicted to be generally satisfied with these areas of their life whereas mobile couples were expected to report dissatisfaction. While the mobile couples may have the most difficulty in setting roots in their community, homes and friends, they may be able to meet much of the developmental need through their commitments to their children and their spouses. Since the military officers can typically take their children and spouse with them when they relocate, it is predicted that there will be less difference between mobile and non-mobile individuals on how satisfied they are with their children, spouses, and marriage. 
Differences in career satisfaction are more difficult to predict because military careers appear to have a differential impact on the developmental needs of males in their 30s. On the one hand, military mobility does not have a negative impact on setting roots in a career, but rather the officer's career is generally enhanced by new and varied assignments. On the other hand, there is reason to believe that the military structure demands more of a team effort and may interfere or even actively stifle the need to be one's own man that is a critical issue in the $30 \mathrm{~s}$. If there are differences in career satisfaction between the military and civilian groups, it is predicted that dissatisfaction with career in the military will be due to problems with becoming one's own man rather than due to forced mobility.

Job satisfaction, on the other hand, can be affected by mobility. The non-mobile worker has the opportunity to truly put his mark on his job and the mobile military officer does not. It is predicted that this lack of identity with the job will result with less job satisfaction for the mobile group. 


\section{METHOD}

\section{Subjects}

subjects for this study consisted of 20 couples in the military (mobile) and 20 civilian couples living a non-mobile lifestyle. Mean average age of each group was: mobile male, 33.25 ; non-mobile male, 33.00; mobile female, 31.05: non-mobile female, 32.15. Mean educational levels for each group were: mobile male, 17.40 years: non-mobile male, 17.05: mobile female, 15.10; non-mobile female, 15.35. Mean number of children in the mobile families was 2.30 , as compared to 2.20 children for the non-mobile families. The mean gross financial level for the mobile families was $\$ 22,640$, compared to $\$ 30,600$ for the non-mobile families.

Mobile military men in this study were either attending classes at the Naval Postgraduate School in preparation for their next assignments or were officers assigned to duty at Fort Ord, California. School assignments are normal at this time period of the military career. Ten officers were attending classes and included four navy officers, three marine officers, two air force officers and one army officer. The other ten men in the mobile sample were army officers assigned to administrative and leadership positions.

The non-mobile men were primarily occupied in small business activities or were working for themselves, such as a dentist and a financial consultant. Six of these 
non-mobile men had what they considered to be direct personto-person professional work, such as teaching, social work and dentistry. Sixteen of the non-mobile males had attended the U. S. Military Academy, served in the military and resigned their commissions.

A description of the subject population would not be complete without a detailed account of how these subjects were obtained for the study. Potential subjects were contacted through a number of different avenues. Initial contact was attempted through local school systems as planned. Representatives of the Monterey, California school system were contacted and following a discussion of the parameters of the study and review of the Request for Volunteers sheet (Appendix A), permission was obtained to disseminate the request in two of the local elementary schools. One of the schools was located on Ft. Ord, California, and one in Monterey, California. The civilian (non-mobile population) school was judged by the Education Board representatives as servicing a population whose family income was roughly equivalent to the military or mobile population of $\$ 15,000$ to $\$ 20,000$. Each of these schools had a student population of approximately 600 students. Request for Volunteer sheets were sent home with each student and from each school three potential volunteer couples responded by prepaid, addressed envelope. Of these potential volunteers, all three non-mobile couples later chose not to participate and two military families did not 
continue. These potential subjects gave too great a time requirement as the reason for not participating. Two additional military (mobile) elementary schools in the Monterey area were contacted through the Parent Teaching Association. A discussion of child development and the impact of military life on children was presented at PTA meetings and was followed by a request for volunteers for the project. Request for Volunteer forms--now slightly modified (Appendix B) and including a prepaid envelope-were disseminated and approximately 20 couples from each school responded. Approximately 15 of these 40 respondents completed the data collection process. Additional couples were developed through friendship links with the volunteer couples, completing the mobile sample.

An attempt to contact non-mobile couples was made through local business, Chamber of Commerce and Junior Chamber of Commerce activities in the Monterey-Carmel, California area. Representatives of these organizations were contacted and the study explained. Most representatives were receptive and assisted in the dissemination of the Request for Volunteers in their organizations. No volunteers resulted from these contacts. The Civilian Personnel Office and Red Cross volunteers of Ft. Ord were contacted and assisted by printing a notice requesting volunteers (Appendix C). Approximately 20 responses resulted from this notice, but these respondents typically did not fall within the study parameters. The majority 
were separated or divorced individuals asking for information about the study and desiring to be included. Two respondents did fit the study parameters and were included in the study. Contact was made with instructors at Monterey Peninsula College and an extension branch of chapman college on post at Ft. Ord, California. Instructors allowed the presentation of a brief discussion on Current Trends in Adult Development during evening classes and the dissemination of Request for Volunteers sheets. Presentations were made in approximately seven classes resulting in four couples who completed the project. Carmel and Monterey church officials were contacted for possible assistance in volunteer development, but were generally unresponsive, typically stating that they had no time available.

Contact of potential volunteers through the local Association of Graduates from the U. S. Military Academy was recommended by a subject. This listing provided access to non-mobile couples in the Monterey and San Francisco areas. The males in these couples had attended the U. S. Military Academy, completed their military obligation service and had left the mobile-military lifestyle. This roster was obtained and the revised Request for Volunteers sheets, including prepaid, return addressed envelopes and an introductory sheet (Appendix D) were mailed to approximately 70 potential subjects. Response to this mailing resulted in approximately 25 positive responses. These, in turn, provided enough couple 
respondents to complete the non-mobile population of 20 couples.

Since subject couples were recruited from a number of different sources, it might be helpful to summarize where they came from. One mobile couple was obtained through Request for Volunteers sheets sent home from elementary schools with children. Fifteen were obtained through presentations to PTA meetings and four were obtained through friendship links. Two non-mobile couples were obtained through notices in a Civilian Personnel office notice. Four couples were obtained through presentation to evening graduate courses and fourteen were contacted through U. S. Military Academy rosters of academy graduates in the California area. Two of the subjects obtained in evening classes were also academy graduates.

Due to the apparent importance of this factor and the possible impact of number of children, a requirement for participation was that the couple have at least one child. The presence or absence of children has considerable impact upon the couples' reported happiness (Campbell, A., 1975; Campbell, J., 1971). Couples not desiring and not having children report considerably higher satisfaction with life than couples with children. Successive children result in different impact on the husband's and wife's relationship. The first two certainly increase the wife's task. 
Only one couple volunteered in which the woman was the principle breadwinner, therefore, the male is the principle income-earner in all couples in both groups, except this one non-mobile couple in which both husband and wife work.

Non-mobile and mobile groups were compared on a) age of male members; b) number of years married; c) number of children; d) years of education of the male: and e) total income for the couple in the last year.

\section{Procedure}

The solicitation of volunteers began in October 1975. This solicitation continued through June 1976 to ensure that sufficient volunteers would be available to provide 20 couples in each of the mobile and non-mobile samples. Testing and interviewing of the couples continued throughout this period as they came available and were willing to commit time to complete the questionnaire and interview. As potential subjects anticipated being interviewed with their spouse, they reported concern and discomfort. This concern and the potential loss of too many subject couples resulted in the personal interview being made optional.

A modification of the interview format also appeared to be required. Couple members expressed concern about really being able to express their feelings about their marriage in front of their spouse. It was decided that the female would be interviewed at their home in the 
afternoon and the male in the evening by the same-gendered interviewer. This format seemed to work out well. Either due to planning or circumstance the wife was typically out of the house or on another floor when the husband was interviewed. When travel time to the couple was long, the subject couple was interviewed at the same time with interviews being conducted in separate rooms of the home. The interview format resulted in half of the subject couples being interviewed.

Although concern had been expressed about making the interview portion optional, subject procurement seemed to progress smoothly. Making the interview optional seemed to result in increased volunteers for the structured testing and the interviews. Some couples reported that they liked having an option other than participate or not participate. Once the couple decided to participate, they now seemed willing to participate completely.

Some difficulty was encountered with couples in which one of the spouses received the Request for Volunteers sheet and volunteered the couple without the spouse knowing about it. The first knowledge that the uninformed spouse did have was receiving the structured materials in the mail. These couples typically did not complete the study. One couple did not complete the study when materials were lost in the mail and the female was asked to again complete the structured instruments, but she declined. A second woman did complete the structured 
instruments a second time and completed the study.

Considerable interest in participating was received from individuals who were divorced or separated from their spouse. Although the Request for Volunteers materials indicated that this study was being done only with couples, at least 15 single volunteers responded, asking if they could somehow participate.

For those subject couples who were unwilling to participate in the interview, an addendum was included with the battery of paper and pencil tools. This addendum included ratings of six areas of satisfaction (life, job, career, family, marriage, sex), age expectancy and marriage problem areas.

Following a determination that the responding couple fit the criteria for the study, the battery of paper and pencil measures were sent to them. The paper and pencil battery included the addendum if the couple had indicated that an interview was not possible. Each mailed envelope included two identical copies of the battery, an instruction sheet (Appendix E), an additional subject data collection sheet (Appendix F), and two separate prepaid and return addressed envelopes. Each subject was instructed to complete their battery independently and to place their completed papers in the mail within two weeks. The instruction sheet to subjects included the date when the materials should be in the return mails. 
Upon receipt of the envelopes from the couples who would not be interviewed, the materials were scored and tabulated. Upon receipt of the envelopes from the male and female of the couples to be interviewed, the materials were scored and tabulated and the couple was contacted by telephone to determine a time when the interviews could best be completed. The females were typically interviewed in the afternoon hours. An attempt was made to interview the male member on the evening of the female interview, but this was not always possible. Interview of both members was done within three days of each other except in one case.

The interview of the female and male subjects began with a minimum of preliminary small talk and progressed along the guidelines presented in the Interview of Male Subjects (Appendix G) and Interview of Female Subjects (Appendix H).

At the conclusion of the interview, subjects were asked if they desired a copy of the completed paper and if they would be willing to answer a few questions at some time in the future. All subjects responded affirmatively. It was anticipated that future investigation into the effects of a research project upon individual and couple satisfaction might be made.

Tabulation of the results of the information collected in the interview was accomplished. clinical observations that seemed to stand out were also noted 
following the interview. Although subjective in nature, these observations were made to assist in interpretation of the objective measure results of the study.

\section{Instruments}

I. Structured Self-Report Battery (SSRB)

A. Instruction sheet (Appendix E)

B. Personal Data Sheet (Appendix F)

C. Semantic Differential (Appendix I)

Stimulus Variables:
a) self
b) tasks of immediate job
c) career
d) spouse
e) children
f) marriage
g) children's friends
h) children's school
i) owning a house
j) parents
k) staying in this location
1) own personal friends
m) spouse's friends

The major focus of scoring the semantic differential was on the evaluative factor since Osgood et al. (1957) reports that this factor accounts for almost $70 \%$ of the common variance. Four of the 13 stimulus variables (self, spouse, career, marriage) were also scored for the factors 
of potential and activity accounting for approximately $15 \%$ and $13 \%$ of the variance respectively (Osgood et al., 1957). It was decided that an assessment of these four critical areas would provide insight as to whether further investigation of these two factors were warranted on other variables. Due to lack of significant findings with potential and activity factors, further assessment was not done with these factors.

The semantic differential has been shown to be a reliable and valid measure of attitudes (Heise, 1969; Lemon, 1966). Reliability test-retest correlations have been reported to be .85 by Osgood et al. (1957) and even higher by Jenkins, Russell and Suci (1958) for total scores. Warr and Knappen (1968) report split-half reliabilities of .70 and .76 for the evaluative factor, .56 to .75 for potency and .58 to .66 for activity. Shifts of one-half of a unit on the semantic differential were found to indicate different meaning with a confidence interval at the 5\% level (Osgood et al., 1957). Validity of the semantic differential has been confirmed with evidence of strong relationships between scores on the evaluative factor and with Thurstone and Cuttman scales (Osgood et al., 1957) as well as social distance scales (Lemon, 1966).

D. Shostrom's (1964) Personal Orientation Inventory (POI) This instrument was designed to measure selfactualization as defined by Maslow (1968). The self- 
actualized person is expected to be more fully functioning and live a more enriched life than the average person. In his evaluation of measurements of self-esteem and related constructs, Crandall (in Robinson and Shaver, 1974) indicates that the POI has become the best measure of self-actualization.

The POI has been found to discriminate between clinically judged self-actualizing and non-self-actualizing groups (Shostrom, 1966). Results found with the POI have been found consistent with the MMPI (Shostrom and Knapp, 1966) and Eysenck Personality Inventory (Knapp, 1965). Although not measuring exactly the same thing, there is consistency between the POI and the MMPI and EPI in direction and significance of measures. The test-retest reliability coefficients have been found by shostrom (1966) to be .71 for Time Competency and .77 on Inner Direction. Subscales range from .52 on Acceptance of Aggression to .82 on Existentiality.

The POI scales are described in Table 1. The POI consists of 150 two-choice alternative value and behavioral judgments. Each item is scored twice. The first scoring is for the basic scales of inner-directed support and time competence. The second scoring is for the ten subscale scores. Two ratio scores are developed. The Time Ratio is obtained by dividing Time Competence by Time Incompetence. The support Ratio is developed by dividing Inner support by other support. 
TABLE 1

Personal Orientation Inventory scoring Categories*

\section{Categories}

I. Ratio Scores

Time Incompetence: Time Competence

23 items

Other Support: Inner Support

127 items

II. Sub-Scales

Self-Actualizing Value

26 items

Existentiality

32 items

Feelings Reactivity

23 items

Spontaneity

18 items

Self-Regard

16 items

Self-Acceptance

26 items

\section{Description}

Measures degree to which one is "present" oriented

Measures whether reactivity is towards others or self

Measures affirmation of primary values of selfactualizing person

Measures ability to situationally or existentially react without rigid adherence to principles

Measures sensitivity of responsiveness to one's own needs

Measures freedom to react spontaneously or to be oneself

Measures affirmation of self because of worth or strength

Measures affirmation or acceptance of self in spite of weakness or deficiencies 


\section{TABLE 1 (Cont'a.)}

Categories

Nature of Man

16 items

Synergy

9 items

Acceptance of Aggression

25 items

Capacity for Intimate contact

28 items

\section{Description}

Measures degree of the constructive view of the nature of man, masculinity, femininity

Measures ability to be synergistic, to transcend dichotomies

Measures ability to accept one's natural aggressiveness as opposed to defensiveness. denial and repression of aggression

Measures ability to develop contactful intimate relationships with other human beings, unencumbered by expectations and obligations 
Researchers (Gould, 1972, 1975; Levinson, Darrow. Klein, Levinson, and Mckee, 1974) have indicated that as the individual progresses through the $30^{\prime}$ s transition, he experiences an increasing desire to be his own man and to be oriented more towards the demands coming from within himself than from others. He becomes more aware of his feelings and experiences a moral resentment about not paying, more attention to his inner self.

The areas of personal orientation evaluated on the POI provide information relating to the conflicts found by investigators to occur in the $30^{\prime}$ s transition. The POI provides a scale indicating an overall determination of the individual's personal orientation towards selfactualization.

The following two instruments were not included in the structured Self-Report Battery unless the subject couple indicated that they were unwilling or unavailable for the personal interview. When it was anticipated that the couple would not be interviewed, the areas of satisfaction rating scale and marriage problem areas questionnaire were included in the packet mailed to the subject couple. When the couple was interviewed, these two instruments were completed during the interview.

E. Rating Scale, Areas of Satisfaction (Appendix J) Each subject was provided a sheet with instructions asking him to evaluate six areas of his life. He was asked to rate each of these areas on a scale of 1 (very 
unsatisfied) to 5 (very satisfied). These six areas include:

1) Life satisfaction

2) Present job satisfaction

3) Career satisfaction

4) Family life satisfaction

5) Marriage satisfaction

6) Sexual satisfaction

This sheet also included a question asking the subject to what age he expected to live and provided a blank for his response.

The frequently used single item question of satisfaction has been objected to by some researchers (Bradburn, 1969; Orden and Bradburn, 1968), but other researchers (Harry, 1976) indicate that this method of evaluating satisfaction has great validity and the single item questioning of happiness correlates with the things it should correlate with such as income, social status, social participation and marital satisfaction.

F. Marriage Problem Areas Questionnaire (Appendix M) Each subject was asked to respond to nine areas of possible conflict within a relationship. Each of these nine areas was subdivided into more specific areas of conflict. The subject was asked to respond to each specific area by marking one of five ratings of "not at all" (a concern), "a little", "a fair amount", "much", or "very much". A "N/A" column was included for those 
particular areas that the subject felt were not applicable to their particular situation, such as not having adopted children.

G. Life Evaluation Chart (LEC) (Appendix $K$ and $L$ )

Each subject was asked to construct two LECs on the model of Lowenthal et al. (1975). Since subjects reported being unable to meaningfully relate these graphs, they were dropped from further analysis.

II. Personal Interview Questions (Appendix $\mathrm{G}$ and $\mathrm{H}$ )

The interview guide is stated in question format, but was not presented to the interviewed subject verbatum. The questions provided a topic and sequence guide for the interviewer. This allowed for the interviewer to stay on track and to ensure that all areas of interest were investigated, while at the same time allowed some leeway in pursuing areas that arose during the interview. The female subject was interviewed by a female researcher and the male was interviewed by myself. Appendix $G$ gives the male interview guide and Appendix $H$ provides the female interview guide.

\section{Analysis of Data}

I. Analysis of Sample Group Demographic Data

The mobile and non-mobile groups were compared on age of male member of the couple, years of education of the male member, number of children, and family income. Male and female groups were compared on age and education. 
Means and standard deviations were determined for each variable. A two-way analysis of variance (Winer, 1971) was used to compare each of these measures.

II. Analysis of structured self-Report Battery

The semantic differential was scored according to Osgood's et al. (1957) groupings to determine a total value for the evaluative dimension on each of the variables. This evaluative dimension included 11 of the bipolar scales rated for each aspect of the subject's Iife. Means, standard deviations, and relative rank ratings were determined for these variables. Comparison of rank ratings were determined using a two-way analysis of variance used to compare groups. A sign test was used (winer, 1971) to compare groups on tendency to rate all variables either in a high or low direction.

In addition, four variables (self, career, spouse, marriage) were scored for activity and potential (osgood et al., 1957). Four different bipolar scales contributed to each of these measures. Means and standard deviations were determined for these measures on each group. A two-way analysis of variance was used with these data.

Iife evaluation charts (IEC) proved to be too difficult for subjects to relate to and develop meaningful graphs. The LECs were dropped from further evaluation.

Shostrom's POI was scored according to the instructions in the POI manual (Shostrom, 1966). Means and standard deviations for each of the POI measures provided by each 
group were determined. A two-way analysis of variance was applied to these fourteen measures.

III. Analysis of objective scores from Interview Questions The interview included three questions that resulted in objective measures. These are satisfaction scores, age expectancy, and marriage problem areas.

subjects provided a rating of their satisfaction in six areas (life, career, job, marriage, family, sex). In addition, a total satisfaction score was determined by totaling the six scores given by each subject. Means and standard deviations were determined, and two-way analysis of variance was accomplished with each of these measures.

Mean age expectancies and standard deviations were determined. A two-way analysis of variance of this measure was accomplished.

Subjects were asked to rate nine areas of potential marital problem areas. Each of these areas are subdivided into specific topic areas. Subjects were asked to rate each topic as "not at all" (a problem), "a little", "a fair amount", "much", "very much" or "N/A" (not applicable). The value of 1 was assigned to "not at all", 2 to "a little" continuing to 5 for "very much". N/A responses were not scored or included in determination of means. For example, if only 17 of the 20 subjects in any group answered with scorable responses, then the mean for those 17 was determined. Means and standard deviations for each 
group on each topic were determined. Rank ordering of specific topics within the marriage problem areas were determined. A sign test was applied to evaluate for a tendency of either group to rate their responses in either a positive or negative direction.

Subjects who elected not to be interviewed still provided scores for these areas of satisfaction, age expectancy, and marriage problem areas. Materials were mailed to the subjects with an addendum to collect this information, therefore, scores are available for all subjects.

Overall impressions of interview material were reviewed for comparison against objective measures for consistency and to identify issues that were not investigated with the objective battery. These interview observations and impressions were used to help in clarification of the objective measure results. 


\section{RESULTS}

\section{Sample Group Comparisons}

Sample groups were compared on 1) age of husband;

2) years of education of husband; 3) number of children: and 4) family income. Table 2 provides the means and standard deviations for these data. Table 3 presents the summary table for a two-way analysis of variance applied to each of the demographic measures.

\section{TABLE 2}

Demographic Means and

Standard Deviations for Sample Groups

Male

Mobile Non-mobile Mobile Non-mobile

Age m

sd

Yrs. education

Number of children

Total family compensation
$33.25 \quad 33.00$

(1.13) (1.00)

17.40

(.92)

17.05

(2.13)

31.05

(2.29)

32.15

(1.88)

$15 \cdot 10$

(1.61)

15.35

(1.96)

$$
\begin{array}{ll}
2.30 & 2.20 \\
(.78) & (1.12)
\end{array}
$$

$\begin{array}{lc}22.65 & 30.60 \\ (3.04) & (12.78)\end{array}$

Demographic data indicated that there are no significant differences between the mobile and non-mobile groups on age, years of education, number of children or total family compensation.

As might be expected from general demographic differences in marriage, women were found to be significantly younger and have less education than their spouses. 


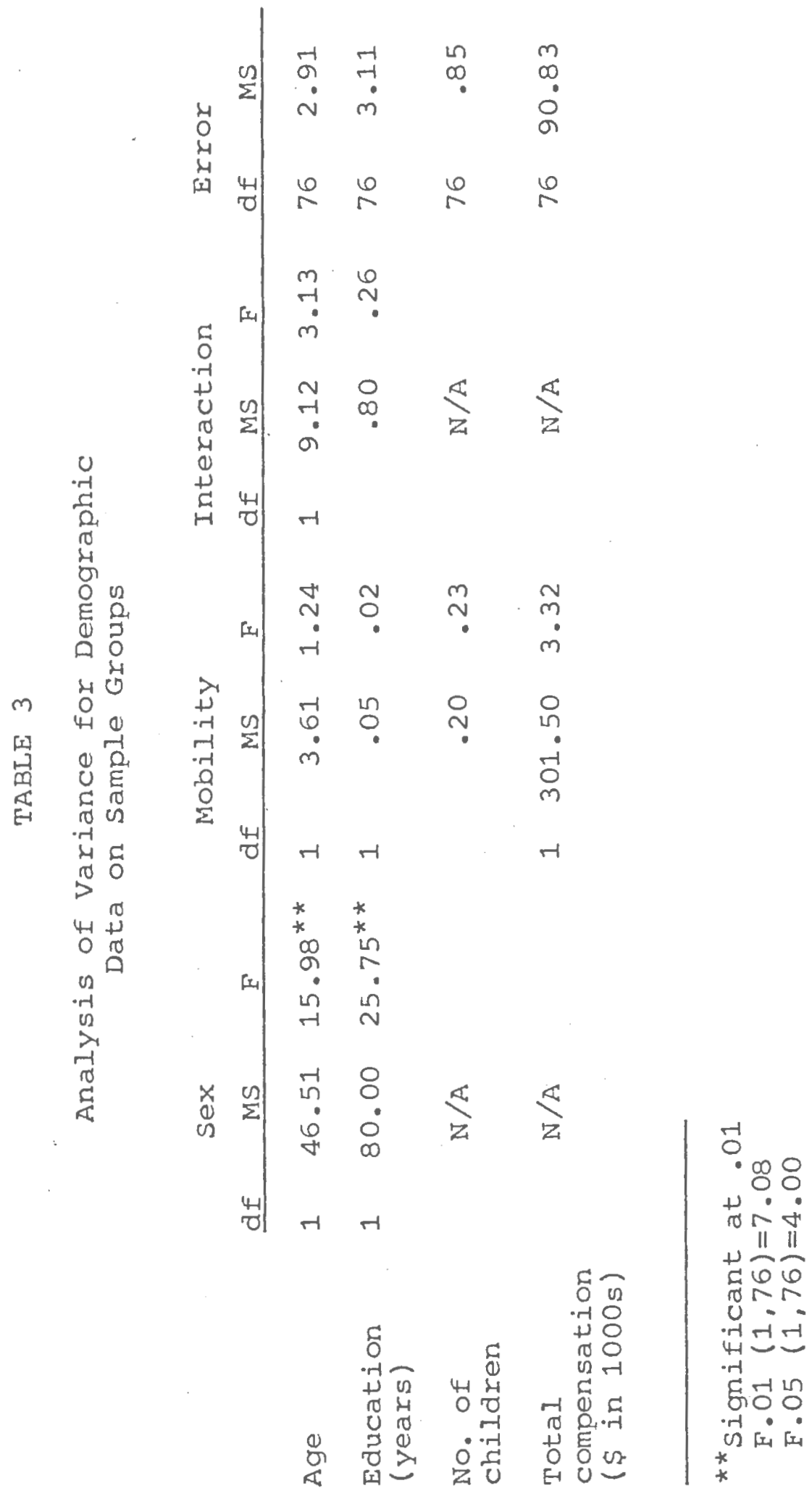


A. Shostrom Personal orientation Inventory (POI)

A two-way analysis of variance was applied to the data resulting from administration of the POI. Means and standard deviations for these data are shown on Table 4. A test for homogeneity of variance on the standard deviations indicated no significant difference on any of these measures. Analysis of variance summary table figures are shown on Table 5 .

\section{TABLE 4}

Mean and Standard Deviation Scores From the Personal orientation Inventory for Mobile and Non-mobile Populations

Male Female Mobile Non-mobile Mobile Non-mobile

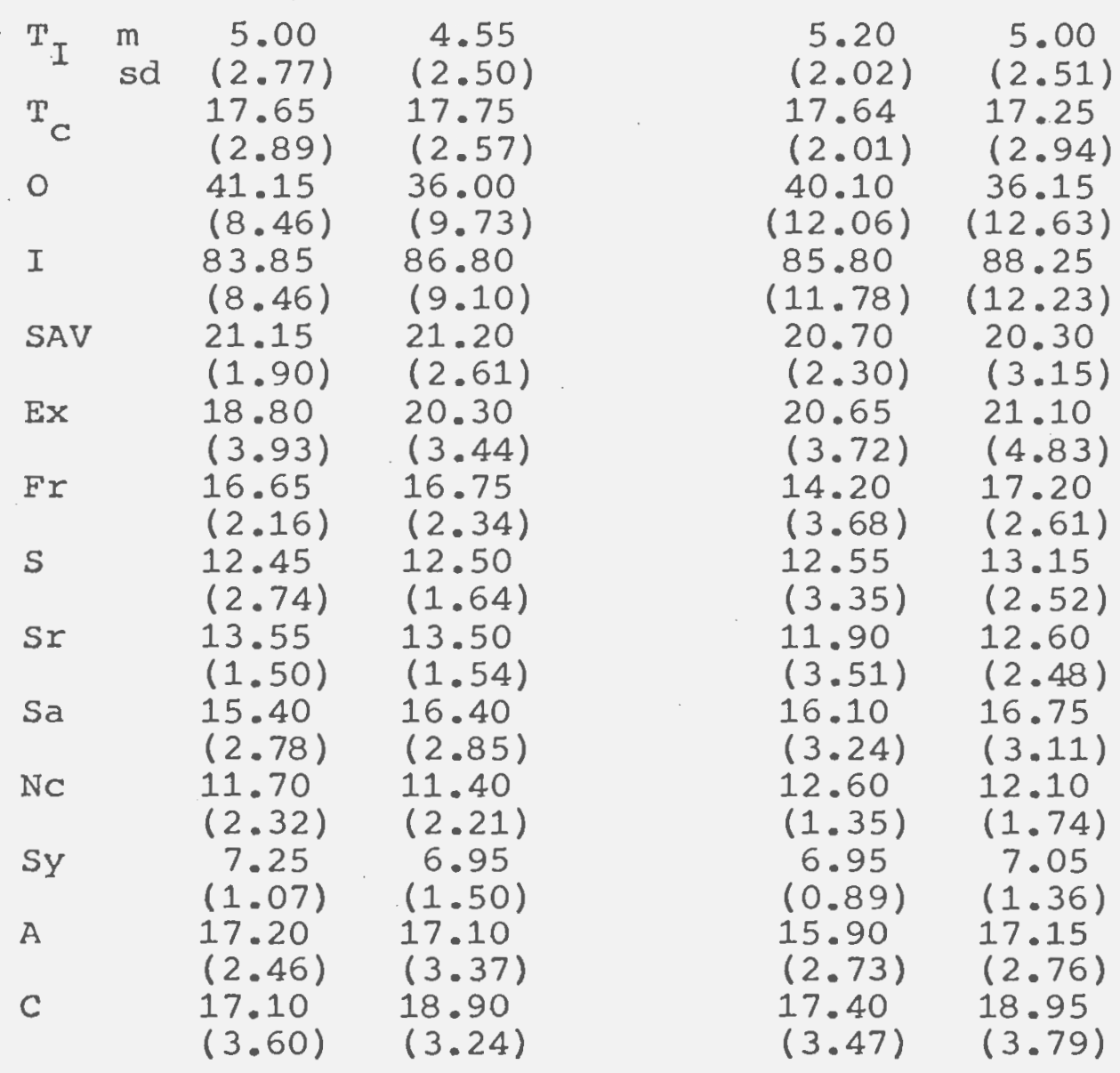




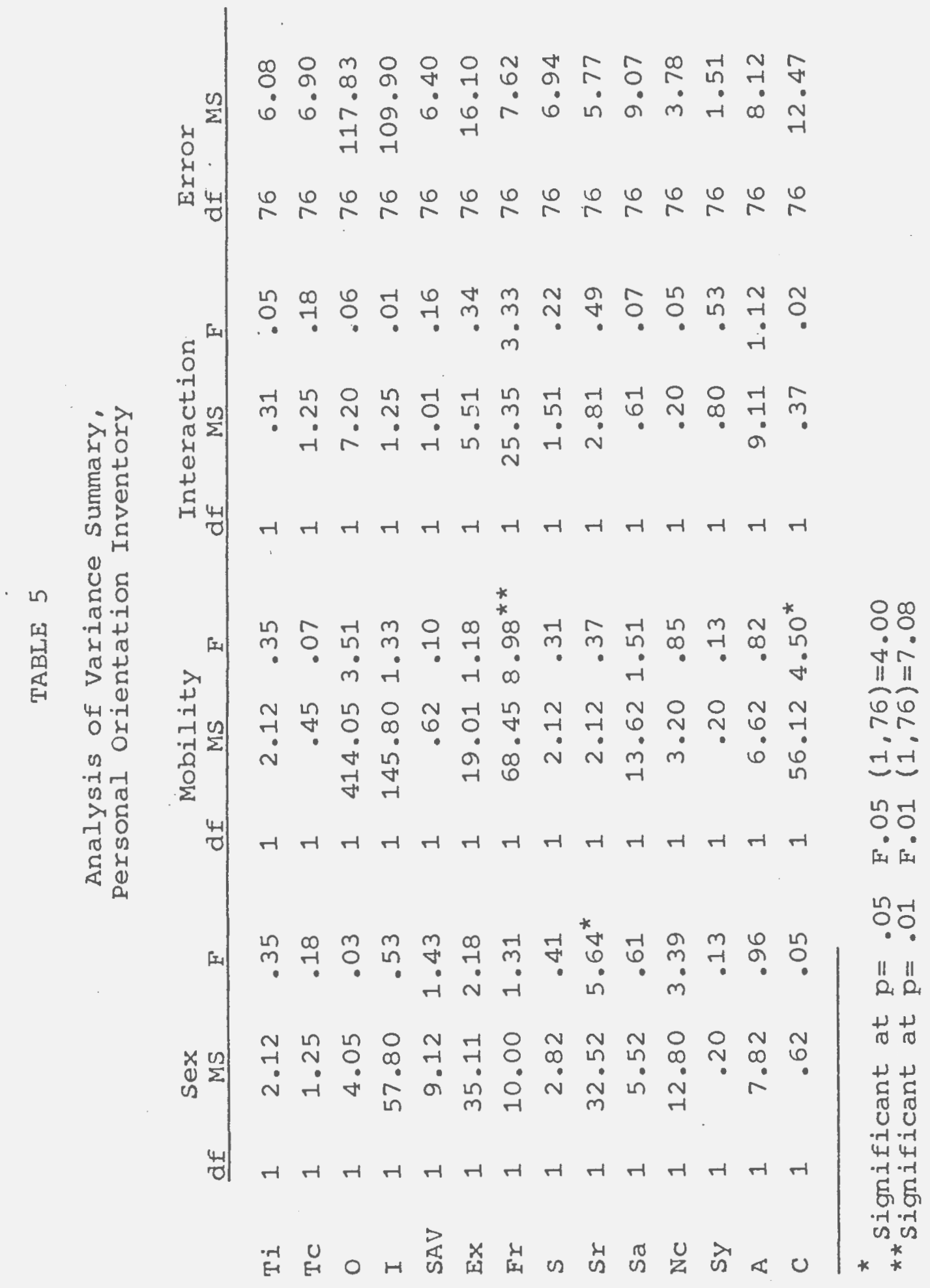


The POI contains two sets of complementary scales. These are time incompetence: time competence resulting in a time ratio score and other related: inner-directed scales resulting in a support ratio. With responses made to all items on the POI, analysis of both scales, such as time incompetence and time competence would be unnecessary. Due to their complementary nature, significant differences found between subject groups on one of the complementary scales would result in significant differences on the other complementary scale. However, it was noted that some subjects left blanks on the POI. Since this might affect the complementary nature of these scales, analysis of variance was completed on all scales.

Table 5 indicates that significant differences were found between the mobile and non-mobile groups on the scales of Feeling Reactivity $\left(\mathrm{F}_{\mathrm{r}}\right)(\mathrm{p}<.01)$ and Capacity for Intimate contact (c) $(p<.05)$.

The differences between the mobile and non-mobile groups on Feeling Reactivity seemed to be accounted for mainly by the differences between the women in each of these groups, since the non-mobile women scored the highest $(\bar{X}=17.20)$ and the mobile women scored the lowest $\left(\frac{m}{X}=14.20\right)$. Significant differences $(p<.05)$ were found between the male and female groups only on self-Regard $\left(S_{r}\right)$. The mobile males scored highest on this 16-item scale with a mean of 13.55. The mobile women provided the lowest mean score with 11.90 . 
It should be noted in Table 5 that on the POI scales, there were significant differences between the groups on only three out of 24 comparisons.

On the POI, Shostrom (1966) has used a time ratio developed from time incompetence/time competence to evaluate the person's ability to live fully in the here and now tying the past and future together in the present in a meaningful way. Shostrom indicated that a time competent person has a ratio of about $1: 8$ as compared to a time incompetent person who overly focuses on past or future events and has a ratio of 1:3. A normal individual is considered to have a ratio of approximately 1:5. Groups in this study were found to have mean time ratios of: mobile male $1: 3.34 ;$ non-mobile male $1: 3.90 ;$ mobile female $1: 3.39 ;$ non-mobile female $1: 3: 45$

The support ratio was developed by Shostrom (1966) to measure one's tendency to be self-motivating versus dependent on others for motivation. Shostrom indicates that a ratio of 1:3 would be found for an actualizing person, approximately $1: 2.5$ for a normal person, and $1: 1.3$ for a non-actualizing person. In this study groups were foud to have mean ratios of: mobile male 1:2.04; non-mobile male $1: 2.41$; mobile female $1: 2.14 ;$ non-mobile female $1: 2.44$.

B. Osgood Semantic Differential

Means and standard deviations for these data are presented in rable 6. A test for homogeneity of variance 
TABLE 6

Mean and Standard Deviation Scores From Osgood Semantic Differential

For Mobile and Non-mobile Populations

Male Female

Evaluative Factor Mobile Non-mobile Mobile Non-mobile

$\operatorname{Self}$

$\mathrm{m}$

5.43

5.65

$(.51)$

5.61

5.44

sd

$(.64)$

5.13

$(.86)$

5.11

5.35

(.93)

5.41
$(.77)$

5.55
$(.80)$

5.70

5.32
$(.79)$

5.93

5.81

(.83)

Spouse

5.92
$(.82)$

$(.85)$

$(.97)$

5.81

Child

5.97

6.30

(.62)

$(.80)$

6.07

(.53)

6.27

(.53)

Marriage

5.81
$(1.02)$

5.80

5.86

5.92

(.99)

$(.94)$

Child's Friends

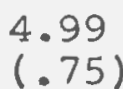

$$
5.27
$$

$(.72)$

5.37

$(.86)$

5.86

Child's school

5.35
$(.82)$

5.71

5.55
$(.77)$

5.66

(.65)

$(.90)$

House Owning

5.45

5.81

$(.97)$

5.29

5.96

(.86)

(.86)

(.69)

Parents

$$
5.45
$$

5.22

(1.10)

(1.34)

5.40

5.34

(.91)

(1.32)

Staying This

Location

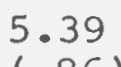

5.48

(1.11)

5.10

5.56

$(.86)$

(1.01)

(.99)

Own Friends

5.62

5.93

5.94
$(.57)$

6.27

(.71)

$(.69)$

$(.44)$

Spouse's Friends

5.41

5.68

$(.66)$

5.45

5.81

$(.87)$

$(.87)$ 
TABLE 6 (Cont'd.)

Male

Female

Activity Factor Mobile Non-mobile Mobile Non-mobile

Self $\mathrm{m}$

4.90

4.81

4.04

4.13

sd

(.73)

$(.67)$

$(.72)$

Career

4.95
$(.71)$

4.83

4.74

$(.69)$

4.98

(.80)

$(.77)$

Spouse

4.50

4.86

(1.16)

(1.25)

5.11

5.09

(.61)

$(1.00)$

Marriage

4.81

5.21

5.08

5.13

(1.00)

(1.12)

$(.90)$

$(.72)$

Potential Factor

self

Career

Spouse

Marriage

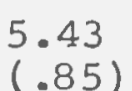

5.36
$(.82)$

5.45
$(.78)$

4.99

(.83)

(.93)

5.74

(.86)

5.48

(1.22)

5.59

(1.09)
5.55

(1.17)
5.35
$(1.09)$
5.41

(.61)

5.45

(.89)

5.54

(1.16)

5.70

$(.85)$ 
on the standard deviations indicated no significant differences on any of these measures. The summary of results from a two-way analysis of variance applied to these data is presented in Table 7.

The summary of results indicates that significant group differences were found on five of the 26 different comparisons. Non-mobile groups were found to give significantly more positive responses on semantic differential stimuli of child's friends $(p<.05)$, owning a house $(p<.05)$ and own friends $(p<.05)$. All three of these differences were found on the evaluative factor of the semantic differential. Women were found to give significantly more positive responses than men to the stimuli of "child's friends" $(p<.01)$ on the evaluative factor and self $(p<.01)$ on the activity factor.

An examination of Table 6 suggested that the nonmobile group was showing a pattern of responding with higher levels of satisfaction than the mobile group, even though many of the differences on specific stimuli were not significant. This pattern was investigated with a sign test (winer, 1971).

Non-mobile male and female subjects were found to indicate greater satisfaction in 21 out of 25 evaluative measures (one tie was recorded in the total of 26 measures). The probability of this occurring due to chance was determined with a sign test to be less than .01. Since the significant differences found in this pattern might be accounted for by those measures already 


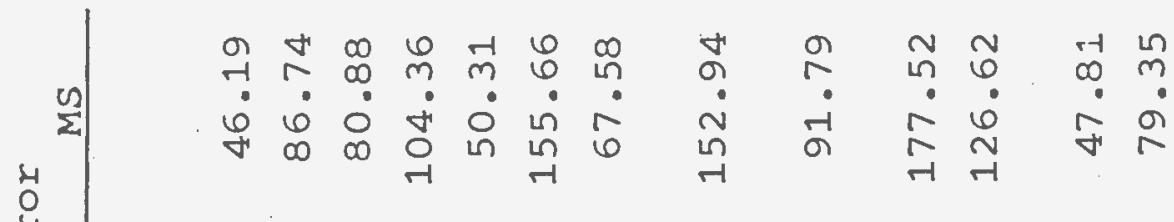

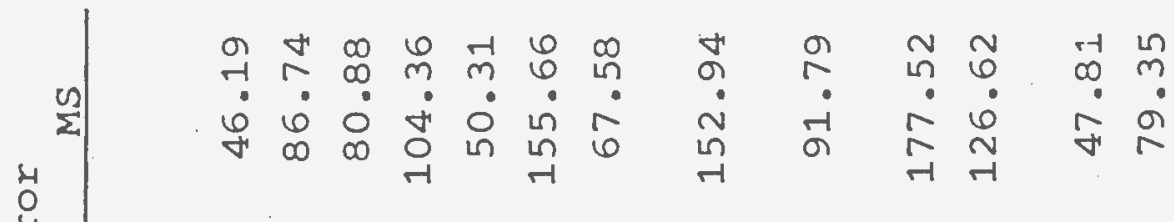

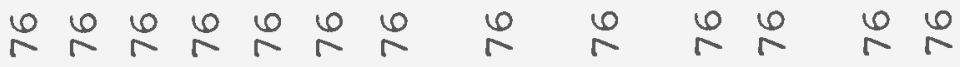

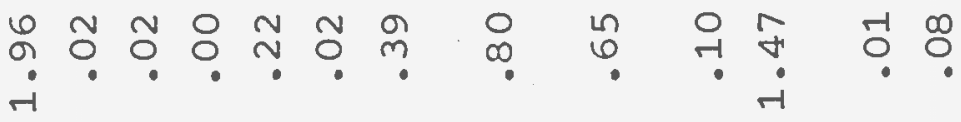

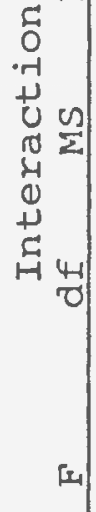

(1) 4

$\therefore \quad 0.4$

(4) न

त.

$>+$

$4 \pi$

○

ถ)

$\sum_{\substack{1 \\ 0}} 0$

긍

公 0

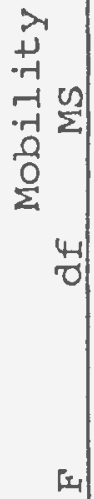

ผ

4

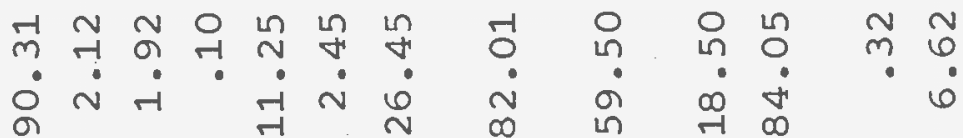

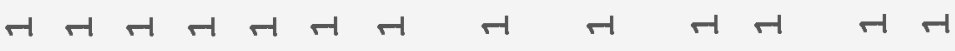

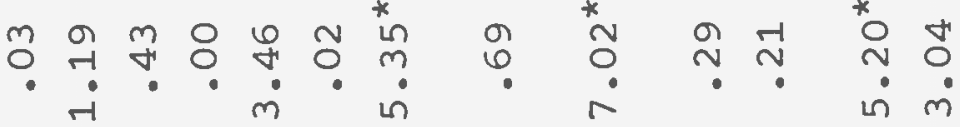

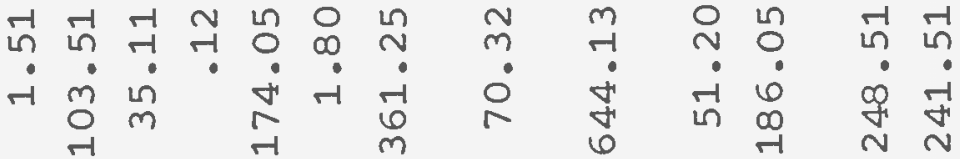

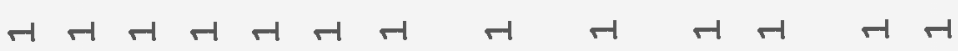

•

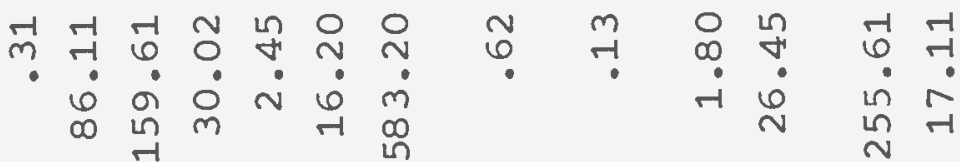

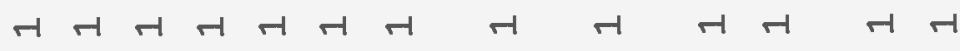

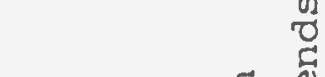

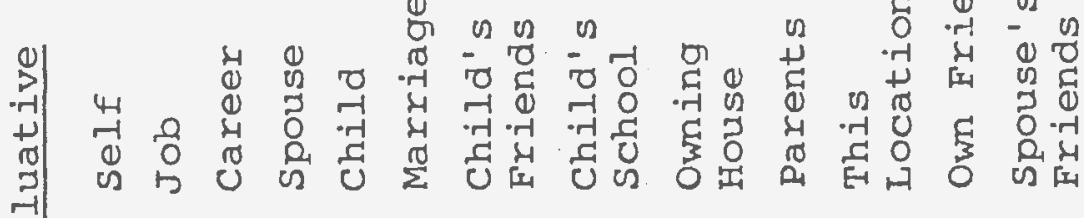

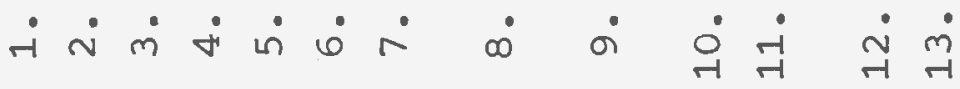




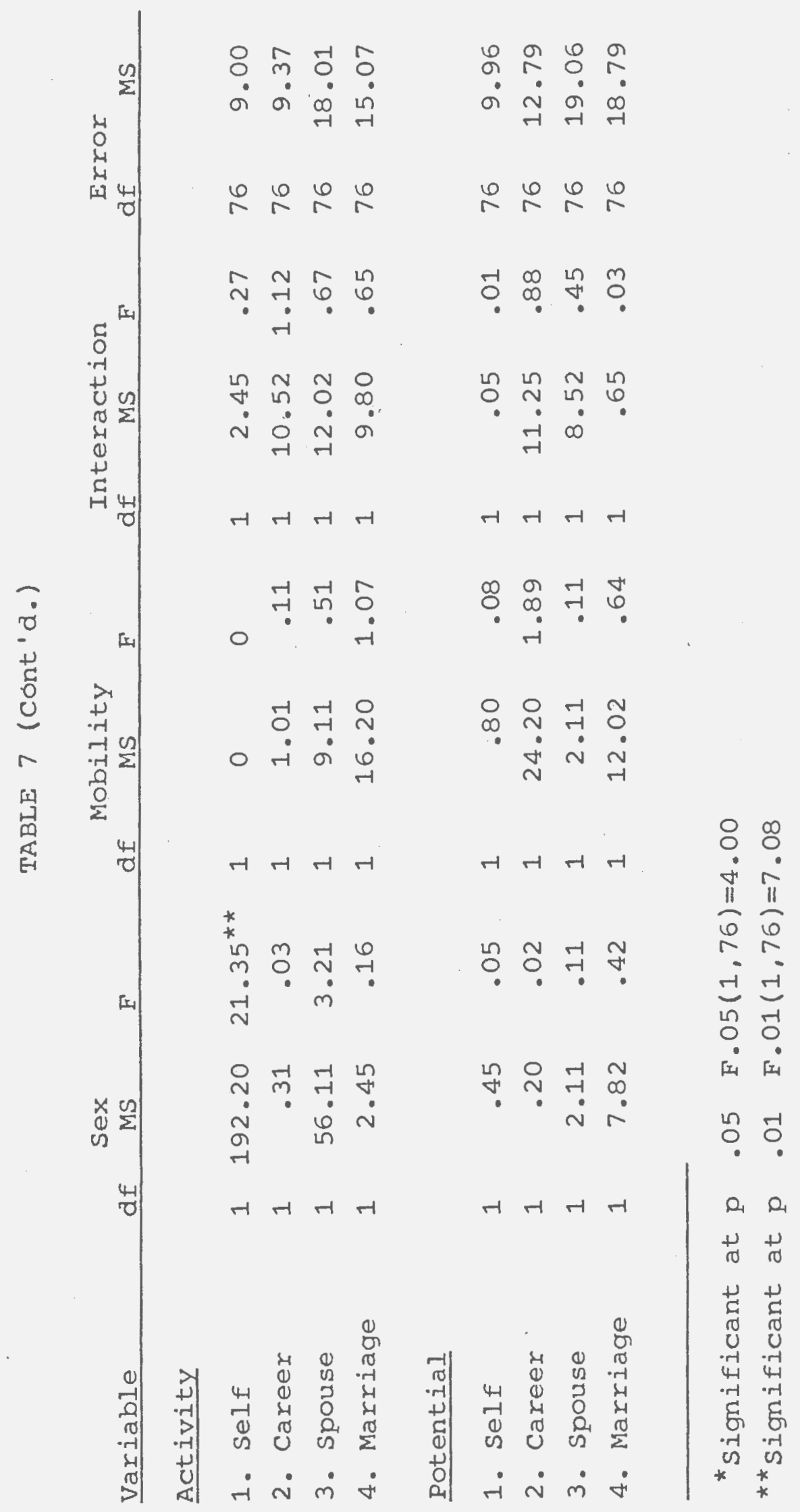


found to be significantly different, these significant differences were eliminated. With this elimination 15 out of 19 measures were scored in a more positive direction for the non-mobile groups. The probability of this occurring due to chance alone is still less than .01 .

Female versus male comparisons within each mobility group resulted in a finding that females reported higher levels of satisfaction on 18 of 26 comparisons. The probability of this occurring is less than .04. Elimination of those measures already found to be significant resulted in women reporting higher satisfaction in 13 out of 20 measures. The probability of this occurring due to chance alone is greater than .13.

These sign tests were performed to determine if the overall pattern of significance was in the direction of those measures found significant. In general, this direction of pattern from the sign test was consistent with direction of significant measures.

Table 8 presents the stimulus variables of the semantic differential listed in rank order. This rank order was determined by placing the stimulus which received the highest evaluative score at the top of the list and working down through decreasing values. The stimulus receiving the most positive score is located at the top and the least positive at the bottom. It may be noted on Table 8 that each group gave the highest or most positive response to child. Males in 


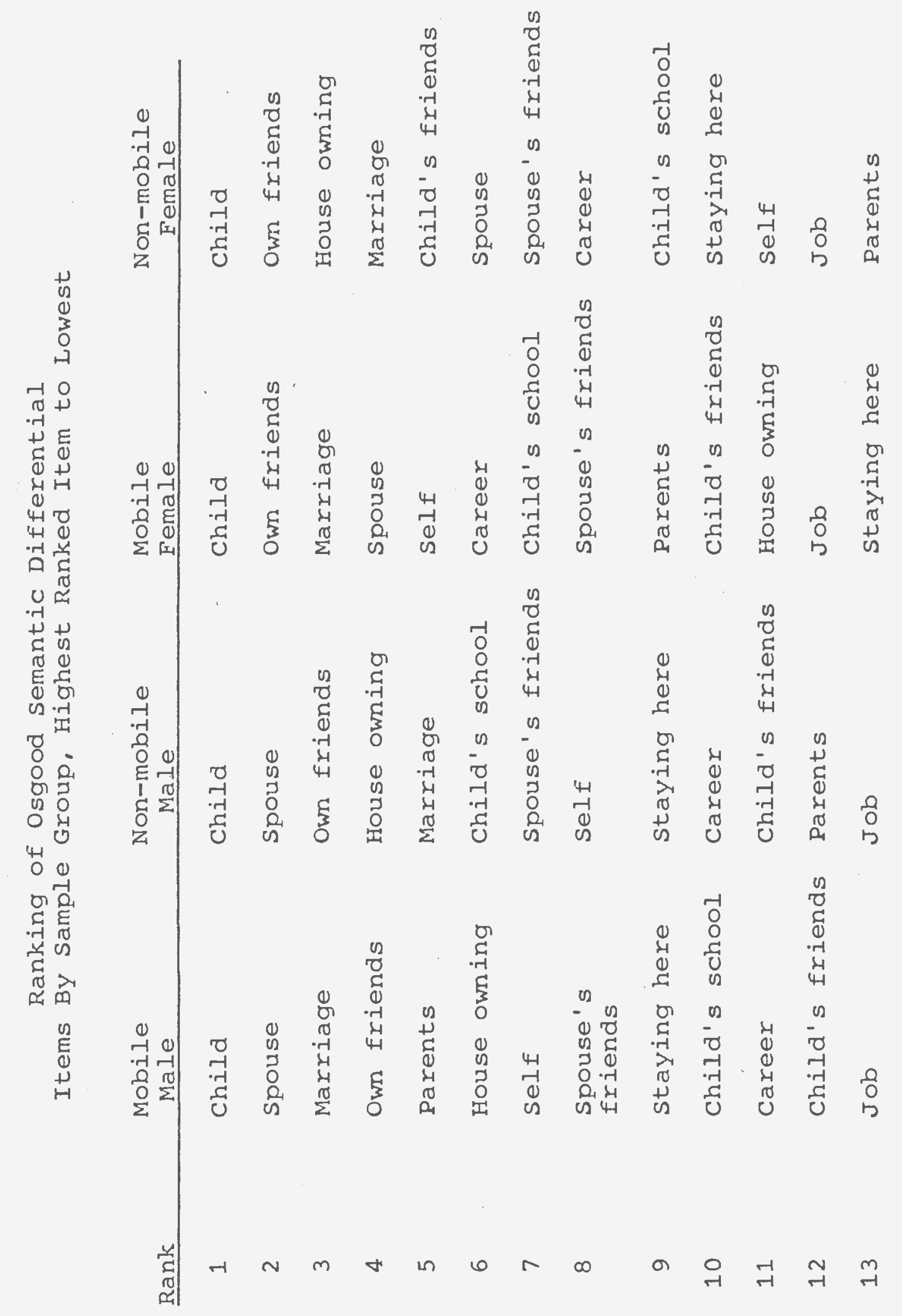


both mobile and non-mobile groups gave the second highest semantic differential scores to the stimulus of spouse, while women in both mobile and non-mobile groups gave the stimulus of own friends as their second highest scores. The stimulus word of job was given the lowest score by the mobile and non-mobile males and the secondto-last by mobile and non-mobile females. It should be noted that although Table 8 provides a ranking from most to least positive scores, none of the scores given by any group fell below a neutral point of five on any of the stimuli. All responses were in a positive direction.

C. Marriage Problem Area Checklist

None of the groups reported that there was a considerable problem in any area of their marriage. Due to the general absence of problems being reported, a qualitative rank ordering was used to indicate which topics received the most concern relative to the others.

A rank ordering of the 67 specific areas of possible concern was determined for each group using mean scores determined from values assigned each of five responses as discussed in Methods. Table 9 presents a rank ordering of the five specific topics receiving the score of most concern. A score of one is a report of the subject experiencing no concern, two is a score of a little concern, and three is a fair amount of concern.

This qualitative comparison indicates that both groups of males report that they are most concerned by 
Five Items of Highest Rated Concern By Sample Group On Marriage Problem Area Checklist

\section{Mobile Male}

1. (I4) Time with (children)

2. (A1) Too little time spent communicating

3. (F2) How (recreation) time will be spent

4. (I3) Discipline (of children)*

5. (C5) How it (money) is spent*

(c4) How much (money) is spent

Non-mobile Male

1. (I4) Time with (children)

2. (A1) Too little time spent communicating

3. (A6) Bitching

4. (I3) Discipline (of children)

5. (C1) Amount (of money)

Mobile Female

1. (I3) Discipline (of children)

2. (A1) Too little time spent communicating

3. (C1) Amount (of money)

4. (C5) How (money) is spent

5. (I4) Time with (children)

Non-mobile Female

1. (A1) Too little time spent communicating

2. (I3) Discipline (of children)

3. (I4) Time with (children)

4. (A6) Bitching

5. (B4) Premature ejaculation ** (C1) Amount (of money)

Note: Item numbers shown within parentheses ${ }^{\star *}$ Tied score 
the amount of time spent with their children. The area of next greatest concern for the males was time for communication. Both groups of females reported communication time as of high concern, with the non-mobile females reporting time for communication as of greatest concern and the mobile women reporting time for communication as the second-highest area of concern. Discipline of the children was listed second by the non-mobile females and was included in the top five problem areas for both male groups. Mobile groups indicated concern over how money is spent while non-mobile groups indicated concern about the amount of money available. Non-mobile groups indicated that manner of communication or bitching was a problem for them.

Further investigation of the qualitative data with a sign test indicated that the non-mobile males reported more concern than that reported by the mobile males, 52 out of 67 times. The probability of this occurring due to chance alone is less than .01 . Non-mobile women showed no tendency to respond in one direction over the mobile women.

D. Satisfaction scale

A two-way analysis of variance was applied to the data resulting from the satisfaction scale. Means and standard deviations are presented in Table 10. Table 11 presents a summary of the analysis of this data. 
TABLE 10

Mean and Standard Deviation Scores

From Satisfaction Rating Scale

of Mobile and Non-mobile Populations

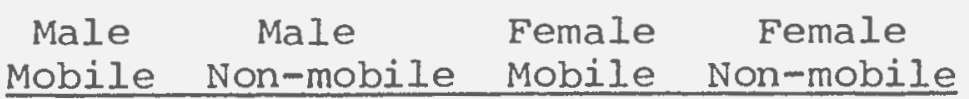

\begin{tabular}{|c|c|c|c|c|}
\hline $\begin{array}{l}\text { 1. Life } \mathrm{m} \\
\mathrm{sd}\end{array}$ & $\begin{array}{l}4.30 \\
(.14)\end{array}$ & $\begin{array}{l}4.15 \\
(.12)\end{array}$ & $\begin{array}{l}4.25 \\
(.16)\end{array}$ & $\begin{array}{l}3.85 \\
(.23)\end{array}$ \\
\hline 2. Career & $\begin{array}{l}4.00 \\
(.21)\end{array}$ & $\begin{array}{l}4.05 \\
(.20)\end{array}$ & $\begin{array}{l}3.80 \\
(.19)\end{array}$ & $\begin{array}{l}3.80 \\
(.20)\end{array}$ \\
\hline 3. Job & $\begin{array}{l}3.70 \\
(.21)\end{array}$ & $\begin{array}{l}3.60 \\
(.23)\end{array}$ & $\begin{array}{l}3.75 \\
(.22)\end{array}$ & $\begin{array}{l}3.80 \\
(.20)\end{array}$ \\
\hline 4. Marriage & $\begin{array}{l}4.45 \\
(.15)\end{array}$ & $\begin{array}{l}4.20 \\
(.20)\end{array}$ & $\begin{array}{l}4.45 \\
(.19)\end{array}$ & $\begin{array}{l}4.05 \\
(.28)\end{array}$ \\
\hline 5. Family & $\begin{array}{l}4.50 \\
(.13)\end{array}$ & $\begin{array}{l}4.35 \\
(.16)\end{array}$ & $\begin{array}{l}4.45 \\
(.15)\end{array}$ & $\begin{array}{l}4.20 \\
(.17)\end{array}$ \\
\hline Sex & $\begin{array}{l}4.25 \\
(.14)\end{array}$ & $\begin{array}{l}4.30 \\
(.20)\end{array}$ & $\begin{array}{l}4.30 \\
(.21)\end{array}$ & $\begin{array}{l}4.05 \\
(.23)\end{array}$ \\
\hline - MEAN TOTAL & $\begin{array}{l}4.19 \\
(.11)\end{array}$ & $\begin{array}{l}4.11 \\
(.11)\end{array}$ & $\begin{array}{l}4.16 \\
(.14)\end{array}$ & $\begin{array}{l}3.96 \\
(.15)\end{array}$ \\
\hline
\end{tabular}




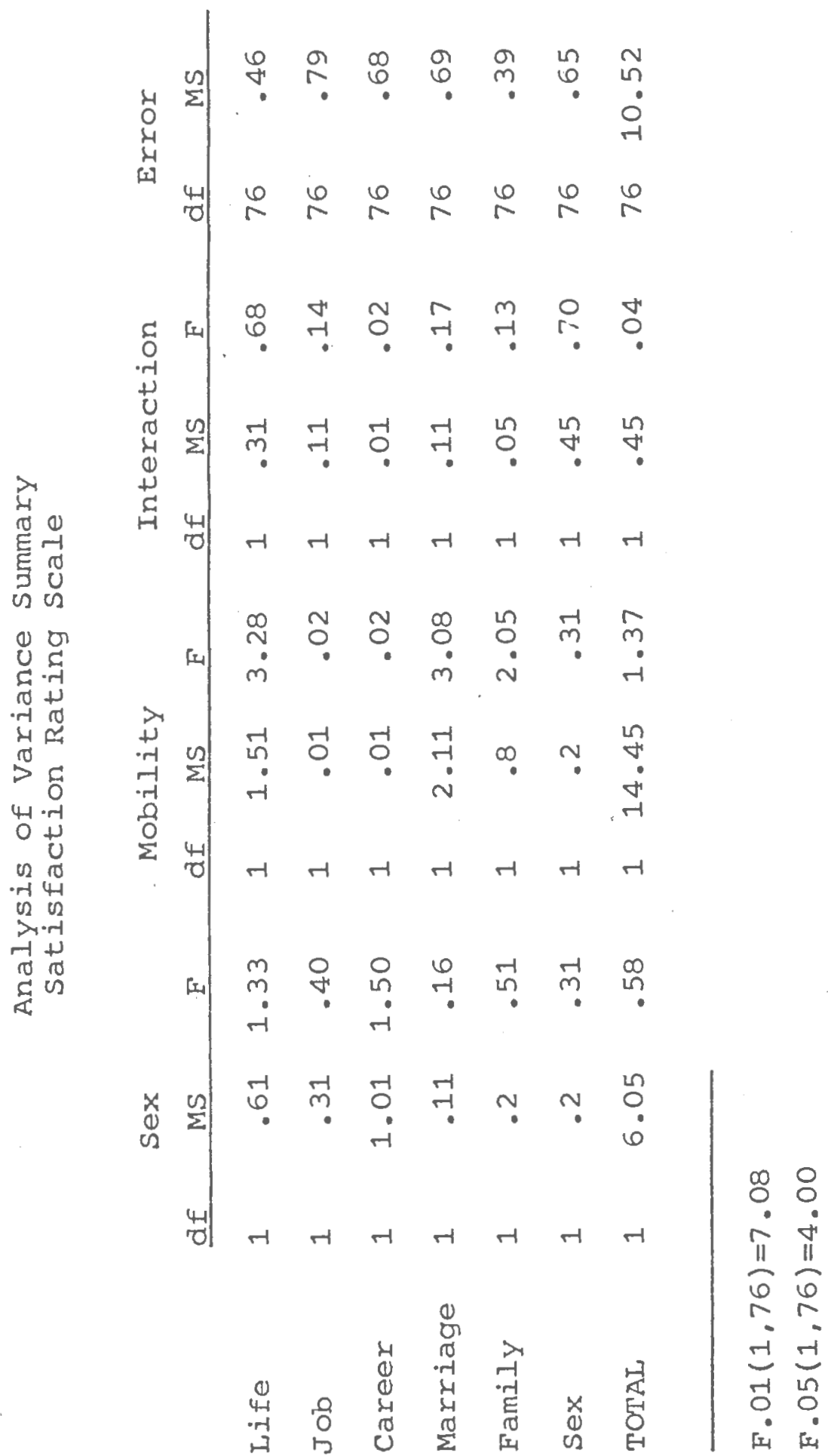

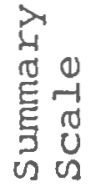

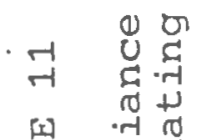

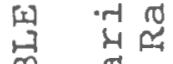

畐 
It may be noted that no significant differences were found between groups on this measure which directly asked the subject to rate his satisfaction in the six areas of life, career, job, marriage, family and sex.

\section{E. Age Expectancy}

Means and standard deviation were determined from data collected in response to the question, "To what age do you expect to live?" The mean and standard deviation values were found to be: mobile male 74.35 (9.99); non-mobile male 77.65 (12.03); mobile female 82.95 (9.93); non-mobile female $83.00(8.91)$. A two-way analysis resulted in a finding of males giving significantly lower age expectancies than females $(p<.01)$. No other significant differences were found.

F. Interview Subjective Impressions

Interview data were examined primarily for any discrepancy between subjective impressions from the interviewers and findings on the objective measures. Interview data were also reviewed to identify any issues that might have been overlooked or not evaluated by the standardized battery.

The overall impression of both interviewers was that the material from the interviews appeared highly consistent with the results from the objective measures. All of the interviewed couples seemed satisfied with their lives and identified only a small number of problem areas. Most of 
these couples appeared committed most to establishing even better relationships with their spouse. They appeared to be normal couples for this stage of life, with some seeming extraordinary in their marital and family relationships. Of the couples interviewed, all but one in the mobile and one in the non-mobile group appeared to be working upon improved relationships within the family. One couple in each group did appear to be involved in moving towards greater disruption than in the direction of settling down of the other couples.

Mobile women appeared quite eager and willing to discuss their lives. The interview of these women had the quality of a release of tension with considerable a ffect including frequent crying or expressions of happiness. It was often difficult for the interviewer to stay on track with the interview guide with these women. The men tended to be more reserved and did not wander from a direct response to the question, although they seemed more willing to talk about their lives than was anticipated. The response of these mobile and nonmobile couples was consistent with the indication of the Marriage Problem Area Checklist, which indicated that time for communication was an important issue.

There were some qualitative issues that stood out in the interview which were not picked up on the objective test battery. The issue of separation of the military officer from his family was found to be quite important, 
but had not been included as a topical area in the Marriage Problem Area Checklist. Many of the mobile wives reported that long separations, not the dislocations, were the things that they liked least about the mobile lifestyle. Short separations of a week or two were seen as giving the couple a little breathing room and letting them get some distance from each other. Longer separations were seen as a burden, with all of the responsibilities of running the household falling to the wife. All of the interviewed males indicated that the worst time of the separation for them was when they left the family. The majority of the interviewed mobile women said that the worst part of the separation for them was when the husband returned and reasserted himself. Neither of these mobile spouses seemed to be aware that their most difficult time of the separation did not coincide with their spouse's anticipated worst time.

Non-mobile couples indicated that a real problem for them was their lack of friends. This issue stood out the most of the concerns that they did raise. These non-mobile couples reported that most of their socializing was done with occupational acquaintances, but that they felt a need to have friends outside of work. 


\section{DISCUSSION}

The mobile and non-mobile couples under investigation in this study indicated that they were generally satisfied with most aspects of their lives. Though the couples were in situationally different groups, they were more similar than they were different. Where these couples do differ, the differences are predictable from the mobile versus non-mobility of their life situations. In the interpretation of these findings, we will first go step-by-step through each of the areas of life satisfaction and then look at the overall pattern that these findings produced.

\section{Marriage and Family}

Each of the four groups in this study reported high satisfaction with spouse and marriage. No significant differences were found in group ratings of spouse or marriage. Satisfaction with spouse and marriage was reflected by high semantic differential and satisfaction scale scores and in personal interviews. This finding of marital satisfaction is consistent with the reports of Gould (1972) and Levinson et al. (1974) that the early $30 \mathrm{~s}$ is a time of renewed commitment and satisfaction in marriage.

Mobile and non-mobile men report high satisfaction with their spouse, second only to satisfaction with their children. During the interview men in both groups identified their marriage and family as the main sources of 
satisfaction in life at this time. This attribution of present life satisfaction primarily to family satisfaction is consistent with the findings of Harry (1976) who found men correlate happiness with intrafamilial activities at this stage of the family cycle.

In the interviews men in both groups identified a feeling of comfort and involvement with their wives as a basic source of marital satisfaction. Men in both groups said that they did not believe they had a companionship or supportive relationship with their wives in the recent past. Many of these mobile and non-mobile men indicated that they had begun to pay more attention to their relationships recently and now felt optimistic and enthusiastic about the direction in which the marriage was going. Mobile men indicated they were encouraging their wives to become more active outside of the homes, expecting this involvement would make the wives happier as well as bring new material into the relationship. Non-mobile men reported a feeling of unity with their wives. This feeling of unity was expressed in a feeling of companionship between the couple and a feeling of facing life situations together. These non-mobile men believed that their wives provided support and encouragement in occupational as well as family areas.

Mobile and non-mobile women also indicated they felt satisfaction in their marriage. In the interviews these women were aware of greater involvement of their husbands in the relationship and found this improved involvement 
to be a source of satisfaction.

In spite of their present satisfaction, women in both groups did indicate that their marriage had not met their premarital expectations. Mobile women said they had expected their husbands to be home more of the time and to be of more help in raising the children. Mobile women thought their husbands would be more available to talk over feelings as well as family management and parental issues. Women in both groups reported in interviews that occupational tasks were taking up too much of the husband's time. These women did not seem to be angry at their husbands and realized that the husbands were very busy. Consistent with the description by Wilensky (1961) of the family cycle crunch, these mobile and nonmobile women wanted more of their husbands' time, but knew the time was not available.

Satisfaction with children appeared to be the greatest source of satisfaction in the lives of mobile and nonmobile men and women. No significant difference was found between group ratings on child or family. Each of the four groups gave the highest semantic differential score to child and the highest satisfaction scale score to family.

In the interviews mobile and non-mobile men expressed considerable enjoyment in watching their children grow and develop, especially at this time when the children seemed to be changing so quickly. These men said that they liked being a part of their children's growth. Men 
did express concern and frustration about lack of time for children. Consistent with Wilensky's (1961) description of the family life cycle crunch and Harry's (1976) view of the demand placed on men's time at this stage, these mobile and non-mobile groups indicated a need to put a lot of hours in on the job and missed not being with the family more.

Mobile and non-mobile women reported in the interviews a feeling that their children were at a good age. The children did not need as much continual care and these women reported enjoying involvement with the children in doing things as well as sharing affection. Many of these women reported that they wanted to make the most of this time with the children, knowing that the children would soon be more involved with activities outside rather than inside of the family.

Although women in both groups indicated that they were enjoying their children, they expressed a desire for greater involvement from their husbands in parenting. On the Marriage Problem Checklist, mobile and non-mobile women indicated that discipline of the children was a problem. These women said in the interview that it was difficult to find time with the husband to arrive at an agreed upon approach to handling problems with the children's behavior.

In summary, it appears that all four groups are involved in marital and family relationships. Men report an increasing interest in the marriage as well as the 
children, but experience frustration due to the lack of time for these relationships. Women report an awareness of renewed interest in the family from their husbands and are also aware of the time squeeze. All groups see their children as the greatest source of satisfaction at this stage in life.

These findings are consistent with the prediction that the mobile group would not differ significantly from the non-mobile groups on marital and family satisfaction, since the family members can remain rooted together even in the face of forced mobility. While there has been a concern that increasing mobility in our society would have a negative impact on marriage and families, the data from this study do not suggest such a negative impact. As we shall see in the career section, the more important variable may be that the family be allowed to remain intact when moves are forthcoming. Why are children and spouses such a high source of satisfaction for individuals in this stage of life? Developmental theorists such as Levinson et al. (1974) and Levinger (1966) would suggest that if the men have accomplished their instrumental roles well in the 20 s, then they will be freer to focus on the affectional aspects of their relationship. As we shall see in the section on careers, the men in this study do indeed seem to have been generally successful in their instrumental roles, and are thus probably freer to put more energy 
into their affectional roles. The interpretation that greater involvement in affectional roles by the males leads to higher marital satisfaction is consistent with the findings of Wills et al. (1974), who observed that males in happy marriages were effective in both instrumental and affectional roles while men in troubled marriages were effective primarily in instrumental roles.

We do not have the data available to determine that satisfaction with marriage and family have changed over time, but the frequent allusions of the subjects to a previously disruptive and less satisfied time in the marriage suggests that this interpretation may well be correct. Nevertheless, before we can conclude that marital satisfaction improves at this stage of life. further research with satisfaction at earlier stages in the marriage and life would have to be accomplished.

\section{Friendships and Community}

Significant differences were found between the mobile and non-mobile groups' rating of satisfaction with own friends, child's friends, and owning a house. Although non-mobile males indicated in the interview that they wanted more friends, the non-mobile couples rated their satisfaction with friends higher than the satisfaction with friends given by the mobile couples.

Mobile couples did report in the interviews that they had many acquaintances spread all over the country, but it was difficult to maintain ongoing friendships. 
With roughly one-third of any military base changing every year, these mobile couples said they felt that as soon as they finished moving in, neighbors and friends were moving out. Mobile males indicated that they would like to have friends, but really did not have time to develop friends outside of work.

Mobile wives seemed more concerned and interested in friendships than their husbands. The semantic differential scores indicated that the mobile as well as the non-mobile women rate their own friends quite high, second only to children. The mobile women expressed a desire for helping as well as confiding kinds of friends. Helping friends were seen as someone who could be called upon in the occupational absences of their husbands to help out with problems such as blown water heaters or dead car batteries. Confiding friends were seen as people with whom the mobile wives could talk over feelings and important thoughts. Many of these women indicated that in the past, when they had first left families and joined the military lifestyle, they had established deep relationships of the confiding kind. After a few occupational moves and experience of dealing with the upset of having the relationships pulled apart, they were less willing to establish these deeper friendships. This report of upset in seeing friendships left behind is consistent with findings in research with military families (Ladycom, 1977 ). 
Non-mobile couples did express considerable involvement with the issue of friendships during the interviews. Nonmobile males were quite direct in saying that they felt an absence of someone to sit down and really talk things over with. These men felt too caught up in their business ventures to seek out friends, but the few friends that they did have were highly valued. These friends were seen as providing support from outside of the family for business as well as personal concerns. Non-mobile women valued friendships in part because they provided support from outside of the family and provided an outlet to the day-to-day routine. These non-mobile women indicated that their friends helped them to take a different outlook or approach to life and gave the wives stimulating things to think about, ranging from childrearing tasks to philosophical issues. These non-mobile wives said they liked having friends in the community who could be counted on. Some other aspects of the community that the mobile and non-mobile couples differed on were their children's friends and owning a house. An understanding of why non-mobile parents rated child's friends and house higher than mobile parents requires an understanding of the different feeling of community that these two groups report.

Mobile couples report liking the convenience and environment of a military post for raising a family. Activities and friendships are seen as transitory. The 
children's friends seem to come and go quickly as families move, and these friends do not seem to have any lasting impact on the children. Mobile women are often involved in wives' groups and clubs or volunteer work in activities on post such as Red Cross or hospital clinics. These couples report that they do not feel in a position to influence the conduct of running the community since that is an official position assigned to a military officer.

These mobile couples do feel a need to keep their little section of the community going. This usually consists of maintaining the family and living quarters, extending out into other areas of the community as called upon to keep the activities going. The house is usually provided by the government on the military post, but is usually seen as too small, too close to other houses, or too noisy. Sometimes these military families do move into a house near the military base, when permitted to do so, but the military community usually remains the focus of attention with its commissary, post exchange, and health care privileges, not to mention many activities for the children. The off-post house is usually rented or it is purchased with the idea of a financial gain when the house is sold as the family moves on. From the interviews, most of the on- and off-post houses appeared to be maintained in a minimum, as needed manner, without the appearance of great personal involvement. When the mobile family lived in a house that it intended to return to upon 
leaving the military service, the house appeared to show greater personal involvement from the couple and it was quite similar to homes lived in by the non-mobile families. Community for the non-mobile couples included aspects which they believed would influence their families. One avenue of influence was seen through friends of the nonmobile children. The children's friends were seen by the non-mobile parents as peers with whom the non-mobile children would be growing up and would have considerable lasting influence. The satisfaction expressed by the non-mobile group on children's friends is indicative that these parents find satisfaction in the influence these community children are having on their own, non-mobile children.

The non-mobile couples believed that their involvements in the community would also be a source of influence on the family. These civilian couples indicated a desire to become more involved with politics in the community as well as being involved in their children's schools. Some of the non-mobile couples reported that they were presently actively involved in seeking leadership opportunities in community or government institutions which would allow them to influence the direction in which their community would grow and develop.

The concern and involvement in community was also expressed as a desire to share the quality of life that the couples were experiencing. Non-mobile men questioned how much they were really contributing to the welfare of 
others in the community. This concern ranged from one non-mobile male's concern that his business was making products which would probably be used by the military to a desire to be involved in volunteer work and with helping agencies. Those non-mobile men who were working in people-oriented professional services reported that they found considerable satisfaction in providing a service to other people. These reports are consistent with Erickson's (1968) view that adults develop to a stage where they have concern for guiding and helping the next generation and other people in general. These non-mobile men seem to be initiating the struggle with the issue of generativity.

The non-mobile couples report that they are enjoying owning their houses and being able to personalize them. They described this personalization of the house as the house becoming a part of themselves. This satisfaction was reflected in the satisfied rating the non-mobile couples gave to their homes on the semantic differential. Interviews seemed to confirm this satisfaction. The non-mobile couples' homes looked lived in and had many personal touches. The non-mobile couples frequently displayed pride in these homes, often inviting the interviewer to see the whole house. These homes seemed to be the secure and permanent base for the family's extensions into other areas of the communities.

The difference between the mobile and non-mobile groups upon their level of satisfaction with their families, 
their children's friends and owning a house seems to reflect the different view of community held by these two different groups. Mobile couples appear to see their community as a place to have their needs taken care of while they complete an assignment. The mobile couples view a community as providing a place to live, to shop, to take care of medical needs and to provide temporary activities for the children and wives. This view of the community is consistent with the view of community attributed to military families by other writers (Just, 1970; Dobrofsky \& Batterson, 1977). The non-mobile group reports seeing the community as having considerable impact on their lives and lives of their children. These non-mobile couples desire to establish greater involvement in the community, and consistent with the views of Gould (1972) and Levinson et al. (1974), are actively establishing roots into the community.

The findings that non-mobile couples find greater satisfaction in their own friends, the friends of their children, and in owning a house are consistent with the prediction that non-mobile individuals would report greater satisfaction than mobile individuals on those aspects of their lives that would be left behind in dislocations to new areas.

\section{Career}

No significant differences were found between the four groups on their ratings of career satisfaction. In 
the interviews, mobile and non-mobile males report slightly different aspects that they attribute to satisfaction in their careers. Mobile males reported to feel a unique commitment that they had not previously experienced. These military officers frequently reported that they originally got into a military career to please important other people or in pursuit of some idealistic goal. Consistent with Gould's (1972) view these men reported that they felt weary of devotion to what they are supposed to be and have come to the realization that they did not know why they were remaining in the military. These men said that the realization of this lack of identity resulted in considerable turmoil as they tried to decide whether to stay in or get out of the military. Most of those interviewed reported a personal sense of commitment and refound identity with the military career. These men reported that they were no longer staying in the military because they had to or because others expected it. These officers said they were staying in the military because they wanted to and found the career personally satisfying. These men may have identified new personal goals for themselves in their career and were found to be busy planning and moving towards career goals at this early 30 s time. These mobile men report that they have begun to focus on more of the positive aspects of the career lifestyle and be less caught up with problem areas and irritants.

Mobile males indicated that they liked having a career that gave them the chance to experience a variety of 
different jobs and the chance to meet new challenges every time they began a new job. These military officers liked the exposure they got and liked being able to travel with their families to new settings. Most mobile men thought that the exposure to other people and places was growthproducing for themselves and their families. Only one of these men reported that dislocations were a source of career dissatisfaction. These men also reported that they liked being part of a team effort and found that aspect of the career satisfying. These mobile men liked the feeling that they were working for and needed by the nation. Many men also reported that they liked being in a career that offered advancement, but most reported no well-defined career goals. The career goals that were expressed usually concerned a desire for higher rank and influence over a larger number of people. The mobile military officers reported that the greatest source of dissatisfaction in their careers was knowing that the careers required separation from the families.

Non-mobile men reported that they liked working alone or working at high levels of small businesses. Most of these men felt they had the responsibility and authority equal to their positions in the occupation. They liked being in positions where they could have a direct influence on the direction their businesses would take and they liked being valued by their working associates. Many non-mobile men reported their present line of work had provided the opportunity to re-establish a sense of self- 
confidence that had been lost in other ventures. This reported sense of regained confidence was especially true of the Military Academy graduates who had later resigned their commissions and had become civilians. Some of these men identified problem areas in their occupation at this stage as requiring too much time, too repetitive, and having to wait too long for higher positions to open up in the business. Although these men said that they really did not have a career, they did make a distinction between the day-to-day activities and the future they had for themselves in their occupation. Although not well defined, most non-mobile males wanted to be successful and to have enough money not to have to worry about making more money. These views of career satisfaction and commitment in mobile and non-mobile men are consistent with the findings of Levinson et al. (1974) who see the early 30 s as a period of settling down and making a niche in society. Men are found to make long-range goals and to develop an inner timetable for the attainment of these goals. Men in both groups report experiencing a time crunch (Wilensky, 1961) and, as Harry (1976) has pointed out, these men continue to be quite active in occupational activities at this family stage as well as try to put time into the family as well.

Women in both mobile and non-mobile groups repurted that they did not have careers, but when asked to name a career they said being mothers and wives seemed like a career as well as a job to them. This association of 
career with family probably accounts for why women tended to indicate a high level of satisfaction with career. In adaition to their own career, mobile women frequently reported they were aware of earlier occupational turmoil their husbands had experienced. These women felt caught up in the turmoil that would affect the future of the families and these women usually reported that they helped their husbands look at alternatives to the occupation and Iifestyle.' Upon finding a solution of remaining in the military career, these mobile women reported that they developed a greater commitment to the career of their husbands and to the lifestyle. This commitment to the military career was a change from an alienation to the military that many reported feeling. Many of these wives reported feeling a greater freedom to enjoy their role as military wife if they wanted to. This attitude of getting involved if they wanted to, but not because they had to, seemed to free up energy. These mobile women reported that with this feeling of freedom they were more likely to get involved with post activities now than they previously had been. This report is consistent with that of Mckain (1973) who found that military wives who did not feel alienated were more likely to participate in military community activities as well as experience happier marriages. Mckain also found that highly alienated military wives were also found to experience the forced moves to be the most disagreeable part of the military. 
The mobile women in this study did not find the dislocations to be a source of dissatisfaction in the military career, but they did agree with their husbands that separations were a problem. The most striking aspect of the separations was that the separations appeared to be experienced quite differently by the husband and wife.

Almost all of the mobile husbands indicated that the worst part of the occupational separation for them was when they actually left the family. They attributed this as being the worst part due to two major factors. One cause for upset was a feeling that they were abandoning their family. They said they felt they were leaving the wife with the whole burden of running the family and making all the decisions. They really did not know what their absence would do to the children, especially when they were gone on the longer 13-month separations, but they did seem to worry about the effect. This feeling also contained guilt for having to leave the wife to fend for the family. The second aspect they described was of their own loss. These mobile men initially experienced a lack of being taken care of and having things done for them. This was experienced as uncomfortable, but often led to a realization that they had pretty much taken the creature comforts of living at home for granted. They found the return to home to be quite satisfying. They felt back in charge and able to influence the children as well as have their own needs taken care of. 
The majority of the mobile wives believed that the worst time of the separation for them was when the husbands returned home. They did not deny that his leaving was upsetting, it was just that his return was worse. In the husbands' absence these wives believe they became quite confident in their ability to handle situations and to run the family by themselves. They felt good about being able to meet the challenge and felt considerable growth in confidence and self-esteem. In the absence of their husbands, these wives reported that good relationships developed with neighbors who soon became important friends.

The return of the husband caused three things to happen at the same time. The first thing that happened was that the husband expected the wife to immediately step back to a position she occupied in the family when he left. These wives reported that there appeared to be no negotiation, the husband returned and took over leadership of the family without even trying to work through the dethroning of the wife. The mobile women reported that the next thing that typically happened was the husband saw behaviors or characteristics in the children that he quickly attributed to the wife's management of the children. These behaviors that he did not like were generally dealt with rather harshly for the child and observing mother. Parental arguments often followed at this point. The last thing to happen was the rapid 
movement to a new working location, requiring the wife to terminate friendships that she had developed in the neighborhood. The husband typically did not know her friends and had little attachment to them. The combination of all three of these events appeared to account for the wife's report that the husband's return was the most upsetting part of the separation.

Discussion with the mobile subjects indicated that neither the wife nor the husband was aware that the most difficult time in the separation for their spouse was markedly different from their own most upsetting time. Both husband and wife indicated that had they known a different part of the separation was more difficult for their spouse, they might have been more sensitive to their spouse's needs.

Mobile and non-mobile men did not indicate significant differences in career satisfaction. Consistent with the findings of Gould (1972) and Levinson et al. (1974), men in both groups appear to find satisfaction in their career and to be committed to the career. These findings of no significant difference in career satisfaction between mobile and non-mobile men support the prediction that no differences would be found between groups on those aspects of life that can be continued in the face of forced mobility.

Job

The semantic differential indicated that there was no significant difference between the mobile and non-mobile 
males in their reported level of satisfaction with job. In ranking the groups' responses to the semantic differential, we found that job fell at the bottom of the mobile and non-mobile men's lists. There appeared to be areas of agreement between these two groups on sources of satisfaction in their jobs.

Mobile males reported that they were now finding the time to focus upon interpersonal aspects of the job which had been previously overlooked and they found this focus satisfying. Many of the mobile men reported that they liked accomplishing one more rung on the ladder towards success in their career. The officers in school particularly liked the hours of their present job, because it gave them more time to spend with their families. Officers not in school or those who were having difficulty with job assignments thought that their present job took up too much time and they did not have time for their families. Many of this mobile male group reported that lack of good role models in the job was a source of dissatisfaction. They did not feel that they were getting the guidance and support that they wanted in their job.

Non-mobile males also reported interpersonal relationships on the job as a source of satisfaction. They reported that they valued their peers and that they felt valued by their peers. Another important source of satisfaction was feeling that the non-mobile men's area of responsibility 
was identified and that they had control of the resources to do their job. These men liked being able to manage the people and materials, knowing that the outcome was a direct result of their efforts. The major source of dissatisfaction was the high pressure pace felt on their civilian jobs. These non-mobile men felt that the frustrations developed from this pace were often taken home and caused disruptions there. These men felt that the job took up too much of their time from the family, but they had made the decision to commit the majority of their time to the job.

Mobile military officers and non-mobile civilian workers reported satisfaction with their present level of accomplishments on the job. Mobile men typically indicated in the interviews that nothing stood in their way of future successes and they felt good about the level they had attained. Non-mobile men reported feeling control over their business situations and said they felt they were being paid well for their occupational efforts. The reports of feelings of accomplishment and focus upon interpersonal aspects of the job are consistent with Gould's (1972) finding that by the time a man reaches 30 , he can pretty well gauge his level of success in business and he begins to focus on other things. similarly, Fengler (1973) indicates that once the man has been able to meet his instrumental needs, he is free to pay more attention to his affectional needs. 
Both groups of men indicate that their jobs are satisfying, but they also indicate that their focus is on other aspects of their lives, such as family and future aspects of the career. The focus of men in both groups on the career and family may account for why no differences were found between the two groups on job satisfaction. Mobile men indicate that they like getting one more step in their career accomplished and tend to focus on this career-enhancing aspect of the job. Non-mobile men report feeling committed to getting the business going and that movement begins with this job. Mobile men appeared to be looking forward to the next job and did not think they would miss this rung of the career ladder, while non-mobile men were making a personal investment and extending roots even into the job.

Mobile and non-mobile women had no significant difference between the two groups on satisfaction with job. These mobile and non-mobile women reported that their jobs were taking care of the children, taking care of the house and taking care of their husband. They reported little distinction between career and jobs for themselves, although they tended to focus on day-to-day repetitive duties when talking about job and satisfaction with raising children when talking about career. These women reported not liking the repetitive, boring nature of housework. They said they knew it had to be done; they just did not like it and really did not find the day-to-day routine to be fulfilling. This report is consistent with Bernard 
(1972) who indicates that housework is one of the primary destructive influences on the married woman.

Satisfaction in the job was reported by women in both groups as coming from the product of a nice and clean house, well-mannered and cared for children, and providing for the needs of her husband. When they could sit back and observe the product of their repetitive labors, the women reported satisfaction. If they focused on the specific tasks of the job, these women typically reported dissatisfaction.

Dobrofsky and Batterson (1977) have expressed considerable exasperation in their inability to understand why mobile military wives seem generally unavailable to recruitment by the feminist movement, when women in almost all other institutions have been affected. The solution to this question may be found in the nature of the military wife's role and gives an indication of why military wives are satisfied in their jobs.

Military wives do feel that their behavior can have considerable influence on their husband's career (Just, 1970; Ladycom, 1977). The expectation of the role of military wife is often clearly understood and passed on by more experienced military wives (Just, 1970; Dobrofsky \& Batterson, 1977: Ladycom, 1977). In these roles, women are identified as important to the military community. The awareness of the wife's role expectations frequently is associated with satisfaction at being able 
to perform the role (Luckey, 1960a, 1960b, 1960c). In their paper, Dobrofsky and Batterson (1977) indicate that social movements have the greatest appeal to persons who have weak role identities. The military wives do not have a weak role identity, especially at this early 30's stage of life where they are experiencing greater commitment with their husbands and a commitment to the military career (Gould, 1972; Levinson et al., 1974; Just, 1970). The value placed upon the role of military wife appears to establish an identity for the woman and this identity makes her less needy of an identity provided through a social movement for women. This role is valued by the military and often satisfying to the military wives.

The military wives take their job and role of military wife with them when they move. By its definition, this role includes being able to set up house and take care of the family wherever the military sends the family. This role and identity goes with the military wives as they make the occupation moves. In the sense that the job really is not left behind by the mobile wife, satisfaction is maintained and probably accounts for no difference between the mobile and non-mobile wives in job satisfaction.

\section{Overall Pattern of Response}

Though there were differences between the groups, the most striking finding was that the mobile and non-mobile groups were more similar than they were different. Where differences between these groups are found, they are 
generally accounted for by less satisfaction with those aspects of life that must be left behind in occupational moves.

Couples in mobile and non-mobile groups indicated that they were generally satisfied with all aspects of their lives investigated by this study. Means for all four groups on the semantic differential, as well as the satisfaction scale scores, were in the satisfied direction. These findings of satisfied feelings with life at this early $30^{\prime}$ s stage of life are consistent with the findings of other developmental stage researchers (Gould, 1972; Levinson et al., 1974). Although confronted with different life situations, it appears that mobile and non-mobile individual: generally experience similar satisfaction with life at this early 30 's stage. Nevertheless, some differences between the mobile and non-mobile groups were noted. Mobile groups indicated less satisfaction than non-mobile groups on semantic differential topics of own friends, child's friends, and owning a house. These aspects of the lives of mobile couples had to be left behind in moves to new locations.

Other aspects of mobile couples left behind were parents, spouse's friends, child's school, and job. Since differences were originally expected on these areas of life, further explanation is needed to account for why the mobile and non-mobile groups did not differ on parents, child's school, spouse's friends, and job. 
Both mobile and non-mobile couples lived some distance from parents. Since both groups were in similar situations, with their parents it is understandable that there were no significant differences on satisfaction with parents.

Mobile and non-mobile males indicated in the interview that their spouse's friends were often sources of demands upon the spouses. Men in both groups thought their wives gave in too frequently to these friends, often taking time away from the family. Women in mobile and non-mobile groups also saw their spouse's friends as taking up too much of their husband's time, when time was difficult to find. These similar views of spouses' friends may account for why no significant difference was found between groups.

A finding of no significant difference between mobile and non-mobile groups on their child's school probably reflects the awareness by these parents that considerable normal transition is experienced every year with new teachers and, at some grade levels, new schools. It appears that what these parents are most concerned about is the change of friends of their children rather than the change of school. This concern for changing friends is reflected in the significant difference between mobile and non-mobile groups on child's friends.

Interview data indicated that mobile and non-mobile men view their jobs differently. Mobile men generally see the completion of a job as the completion of one more rung on a ladder towards success in their career. Seen 
in this sense, effective job completion is a source of satisfaction for mobile men. Satisfaction with job reported by non-mobile males in interviews stemmed from enjoyment of interpersonal relationships and a feeling that their present job was the beginning of greater satisfaction in the career. It may be that this different view of job by mobile and non-mobile males resulted in no significant difference between the two groups. Speculation can be made that in the military the reassignment to a new job is seen as growth-enhancing and increasing the officer's breadth, while in the non-mobile civilian occupation remaining with the job and developing interpersonal relationships is seen as growth-enhancing because it establishes the man in depth in the occupational field.

A further review of our ranking of the subjects' responses to the semantic differential indicates that the mobile men's top three areas of satisfaction are areas that go with him when he moves. For mobile women two of the three highest ratings were on areas of life that go with them in a move, namely, children and marriage. The exception for the mobile women was the high rating they gave to their own friends. This pattern of generally higher satisfaction given to those areas that can be taken in the move is not as consistently shown with the nonmobile men and women. Our ranking of semantic differential responses indicated that non-mobile individuals did 
not make a differential rating between those aspects of their lives that would remain or go with them in moves. These findings suggest that if there is a need to set roots in the early 30s, that the mobile couples meet such a need by setting family and career roots rather than geographical or community roots. Perhaps setting roots is a misleading concept in the adult developmental literature. Need to renew commitment may be a more accurate way of interpreting what happens after the 30's transition. Thus, in both mobile and non-mobile groups the individuals can re-commit themselves to family and career even though the mobile group cannot set geographical and community roots.

\section{Self-Actualization}

Independent of how the subjects were relating to various aspects of their lives, we also evaluated how they were relating to themselves. We used the concept of self-actualization as proposed by Maslow (1968) and measured by Shostrom (1966) with the Personal Orientation Inventory (POI).

Results for each of the four groups on the POI provides further evidence for these groups being representative of normal populations. Shostrom (1966) has indicated that when the ratio scores fall within the normal range or when most of the scale scores fall above the normal baseline of 50 , the POI indicates the person is functioning in the normal range of actualization. Most 
of the scale scores for each group fall within close proximity to the baseline of the normal adult sample. The support Ratio indicates how much an individual relies upon others for support and guidance as compared to one's inner direction or self-guidance (Shostrom, 1966). The Support Ratio for each of the four groups is approximately $1: 2.2$ and in the normal range of other versus inner support. The Time Ratio for each of the four groups is approximately $1: 3.4$. According to shostrom, this ratio falls in the non-actualizing range.

A non-actualizing ratio indicates that one is using time in an incompetent way, focusing on the past or the future more than a normal amount (Shostrom, 1966). The fact that the mobile and non-mobile groups focused upon commitments to their families and careers seems consistent with Por Time Ratios that are weighted toward the future. Interview material indicated that many of the couples believed that they had recently negotiated a transition toward greater involvement with family and the establishment of personal career goals. Focusing upon future aspects of the career and towards an improving relationship with spouse is typical and normal for this stage of Iife (Gould, 1972; Levinson et al., 1974). POI Time Ratios are consistent with this early $30^{\prime}$ s stage.

One interpretation of the Time Ratio is that indeed the mobile and non-mobile individuals are not using their time in an actualizing manner. However, since these 
couples seem to be quite normal and satisfied with their lives, perhaps a more appropriate interpretation would be that at different stages in life time gets actualized in different ways. Couples in their 30 s may well be actively actualizing themselves by focusing more on the future than on the present. At other stages, present orientation may be a much more appropriate criteria for effective actualization.

This second interpretation of the Time Ratio might cause us to rethink our ideas of self-actualization and whether the criterion should be the same for all stages. Given the developmental view of adulthood, it may well be important to reconceptualize self-actualization according to the stage the individual is in. If an individual is not paying attention to the future needs in their early 30 s, this person may not be actualizing at all at this point. Later, after this early $30^{\prime} \mathrm{s}$ stage, when the family and career needs are taken care of, there may be greater opportunity for increased attention to the here and now.

The general pattern of responses to the POI indicates that the non-mobile group tends to score slightly higher than the mobile group. The non-mobile men and women gave higher scores than mobile men and women on 21 of 25 measures on the POI. One tied score was recorded. This trend was most significant in the non-mobile group scoring significantly higher than the mobile group on Feeling Reactivity and Capacity for Intimate contact. 
It may be speculated that the tendency of the non-mobile groun to show a greater degree of actualization on the POI is due to the lack of mobile military individuals to reflect inwardly and lack of opportunity to establish deep, contactful relationships with others. These mobile families often seem to be moving, establishing themselves, and then getting ready to move again. An alternative hypothesis is that the individuals who elect to get out of the military lifestyle and settle into non-mobile lifestyles are individuals who were more self-actualized while in the military. This hypothesis requires further investigation. Nonetheless, the mobile and non-mobile couples do not show significantly different profiles on the POI and only a tendency of greater actualization in non-mobile groups is noted.

Overall the POI measures appear to add support to the view that subjects in this study are normal, especially for this stage of development. All four groups are in a range of normal actualization. The few differences between the mobile and non-mobile groups were in a direction similar to those found in the area of life satisfaction (i.e. with the non-mobile group scoring more positively). POI profiles indicate that all four groups are more similar than they are different.

Forced mobility does seem to have some effect on actualization, though less than we might expect for 
couples who are supposedly wanting to actively set roots. Whether this effect is a lasting or more temporary effect will have to be examined through further research. However, in general the fact that the mobile and nonmobile couples look more similar than different would suggest again that the impact of mobility is not an overwhelming one. Whatever the impact of mobility may be, it appears to be of the nature of a weak variable rather than a strong variable.

\section{$\underline{\text { Sex Differences }}$}

Sex differences were not particularly striking in this study. Women were found to indicate significantly higher satisfaction on own friends and owning a house. On the activity factor of self, the women indicated that they felt significantly less active than men.

Contrary to what some other research suggests, such as Bernard (1972), that women are much less satisfied with their marriage and other aspects of their lives than men, our study did not support this. The notion that women dwindle into wives while men grow into husbands did not show up at this stage of the early 30 s. However, we should keep in mind that the major crisis for women is supposed to occur at age 35 (Sheehy, 1972, 1976) and we may not be seeing its effects at this earlier stage.

Women did report significantly greater satisfaction than men on own friends and owning a house. The activity 
factor of the semantic differential indicated that women felt less active than men. Women tended to score higher than men on all areas of satisfaction on the semantic differential.

One significant sex difference that was found in self-actualization was that men scored higher than women on the self-Regard subscale of the POI. This scale was developed to measure an individual's perceived selfworth based on the perception of strengths (shostrom, 1966). This difference would seem consistent with the traditional sex roles of esteem being based on strength more for males than for females.

The level of satisfaction experienced by these wives may well be due to a renewed interest from the husbands in the marital relationship and family (Gould, 1972; Levinson et al., 1974; Harry, 1976) and also from some satisfaction in being able to gauge how well the husbands are meeting their instrumental roles (Gould, 1972).

\section{Limitations of the study}

It is unclear as to whether or not the problem in recruitment of subjects for this study were a result of shortcomings in methods used to reach subjects in the early $30^{\prime}$ s age group or if the problems are a reflection of the situation of the particular age group under investigation in the study. Recruitment of subjects for this study lasted over a one-year period. Many different 
avenues were used to contact subjects, many potential subjects indicated an interest in the study, but often declined indicating that they did not have time to complete the survey or to be interviewed. Wilensky (1961) has indicated that the married couple experiences a considerable squeeze of their time at this stage of the family cycle. The reluctance of couples to volunteer for additional commitments of their time seems consistent with Wilensky's findings.

Levinson et al. (1974) has suggested that the primary focus of these early 30-year old couples is on establishing family relationships and occupational goals. It could be implied that those couples who did volunteer for participation in the study were feeling more secure in their marital relationships and could afford the time away from working on the relationship. Subjects for this study were volunteer couples and we must limit our generalizations to couples willing to participate in investigations of their satisfaction. Ideally, we would have liked to use a random sample of mobile and non-mobile couples in the early 30s, but found this procedure was not feasible.

The satisfaction scale, in which we directly asked subjects to rate their level of satisfaction in six areas of life, appeared to miss discrimination between groups. These differences were determined with more subtle measuring tools. We would recommend the elimination of 
the satisfaction scale for an investigation of specific aspects of life satisfaction.

clearly, mobility is not the only difference between our sample groups of mobile military families and non-mobile civilian families. While we primarily attributed the differences found between the groups in this study to mobility, we are aware that there are other important differences between non-mobile civilian populations and mobile military populations. However, even if we do attribute our findings to other things, such as structure of the job setting, we would still be saying that the situational variables would be accounting for the differences rather than stage variables. Nevertheless, the evidence remains that the mobile and nonmobile groups were more similar than different in life satisfaction and measures of self-actualization.

We caution about generalizations from this study because some of the other writers in developmental stages appear to over-generalize their findings to whole populations. We have found indications that setting roots is a phenomena that may be conceptualized in more than one manner. Our previous beliefs of setting roots requiring permanent establishment in one location may have been the result of over-generalization by other researchers.

Given our method of recruitment of subjects, we have to be quite cautious in making generalizations from this study. At one extreme, the safest generalization would 
be only to very similar populations, such as volunteers who are 1) successful in meeting their instrumental needs; 2) graduates of West point or similar training institutions; 3) couples with young children: and 4) couples from a middle-class socioeconomic level. On the other hand, an argument can be made that similar results would probably be found for a more random sample of couples in their early 30s. This speculation is made not on the basis of the select sample used in this study, but rather on the fact that our results are quite consistent with the high level of satisfaction that developmental theorists such as Gould (1972) and Levinson et al. (1974) find for individuals in their early 30s. The ultimate answer to how far we can generalize with the present results is to replicate the essentials of this study with a more random group of couples in their early $30 \mathrm{~s}$ who are not necessarily in the military or graduates of a military academy. It is uncertain if these results also apply to other stages in the life cycle. Furthermore, it may be possible that mobility has a greater impact when children are older. This aspect requires further investigation with studies at different stages. Longitudinal studies would be most helpful in assessing the differential impact of mobility at different stages of the life cycle. 


\section{Clinical Implications}

A number of clinical implications became obvious as the study progressed. The first, most striking observation was that couples were generally unaware of proposed stages of adult development. Couples said in the interviews that going through the turmoil and changes they had experienced around 30 would have been a lot easier for them if they had felt that it made some sense or was a normal progression of adult or family development. These couples expressed a belief that they could have more adequately prepared for transitions to different stages and worked their way through the turmoil in a more effective way if they had some awareness of what was happening

It is possible that couples have become more aware of adult stages due to Sheehy's (1976) popularization of adult development. Whether the sheehy best-seller helps or not, the counselor still has to be aware of the critical issues involved in each stage to assist an individual or couple work through transitions.

An awareness that couples experiencing different lifestyles may experience the stage issues differently is important to the effectiveness of the counselor. The counselor needs to be aware that there appear to be alternative solutions to the need to set roots in the early 30s. With this awareness of alternative solutions, the counselor will probably be more effective in helping 
individuals in different lifestyles resolve the need to set roots.

A second implication deals with the issue of separation of the military couple as part of the career pattern. Separations were seen as the most upsetting aspect of the military mobile lifestyle by both the husbands and wives. These men and women experience most distress at different time periods of the separation, but did not appear to be aware that their spouses' stress did not coincide with their own peak stress time. This difference in experienced stress as well as the issue of the effect of the separation requires additional investigation. Individuals and agencies working to lessen the effect of separation stress upon these mobile families should be aware that the return of the husband may create as much stress as his departure.

A third implication of this study deals with communication. All four groups in this study indicated that communication with their spouse was a problem. Marriage Problem Checklists indicated that the communication between spouses was one of the areas of most concern in the marriage. In the interviews, individuals expressed a desire to be able to communicate more effectively with their spouse and others. Women in mobile and non-mobile groups appeared quite eager to have someone such as the interviewer to talk to about their present experience of life. Men appeared more eager and interested in talking 
about their lives than was anticinated by the interviewer. Most of the subjects in this study seemed most interested in improving their ability to relate and communicate with other people. As indicated by the review by Hicks and Platt (1970), these individuals appeared to be finding out that their marital satisfaction improved through greater ability to share affectional material with their spouse.

While these mobile and non-mobile couples expect greater conversation to lead to greater happiness, they may be mistaken. For example, Birdwhistell (1970) has found that happy couples do not verbally communicate all that much, on the average only $27 \frac{1}{2}$ minutes a week. What the mobile and non-mobile couples may really be talking about is not so much a need for improved quantity. but a need for improved quality of communication. Availability of marital enrichment and marriage workshops that focus in part on improving the quality of communication may well be an important resource for couples in their early 30 s. 
APPENDICES 
Appendix As "Request for Volunteers" Sheet

Much is known about the stages of childhood and old age, but very little about the time between. Since this area of adulthood comprises so much of our lives, we feel that it is important to understand it better. As researchers in the area we have begun to study this important time. We hope that finding out what is common to all adults will help each of us toward greater self-understanding and growth. The primary focus at this time is with satisfaction in the 32-35 year old age range. We are interested in the areas of your life with which you are satisfied. This will include your family life and your occupational life. We would certainly appreciate your assistance and that of your spouse. Please consider our request and if you are willing to participate, please fill out the questionnaire below and return it to the provided address. (Even if you cannot participate, we would appreciate any comments you might have about investigation in this area.) Participants for the study will be chosen from the information provided on the questionnaire below and asked for a few hours of their time.

Please return to: Will \& Barbara Wilson 1055 Mission Rd. Pebble Beach, CA

Name:

Spouse's Namer

Occupation: Number of Years Marrieds

Number of Children:

Number of Years Education of Husband,

Number of Years Education of Wife:

Do you have the option to stay in this area for the next five years?
Age:

Spouse's Age:

Spouse's Occupation: 
Appendix B, Modified "Request for Volunteers" Sheet

Much is known about the stages of childhood and old age, but very little about the time between. Since this area of adulthood comprises so much of our lives, we feel that it is important to understand it better. As a husband and wife team having degrees in psychology and interested in adult development, we have begun to study this important time. We hope that finding out what is common to all adults will help each of us toward greater self-understanding and growth. The primary focus of our study is life satisfaction in the 32-35 year old age range. We are interested in the areas of life with which you are satisfied. This will include your family life and your occupational life. Information is strictly for research purposes and all information is strictly confidential.

If you will agree to participate and fit the criteria of our study, we will ask you to fill out some questionnaires. After the questionnaires have been completed, a time will be set up for a personal interview lasting approximately one hour. The interview will consist of the wife being interviewed by a female interviewer in the afternoon and the husband being interviewed by a male interviewer in the evening.

We would certainly appreciate your assistance and that of your spouse. Please consider our request and, if you are willing to participate, you need only fill out the first questionnaire below and return it to the provided address in the enclosed envelope. If you cannot participate, we would appreciate any comments you might have about investigation in this area.

Participants for the study will be chosen from the information provided on the questionnaire below.

Please return to: Will \& Barb Wilson

204 Colmar Rd.

Ft. Ord, CA 93941

Phone: 242-2348

Maj. W. I. Wilson

Via Message Center

MEDDAC, M.H.C.S.

Names

Home Address:

Spouse's Name:

Occupation:

No. of Years Marrieds

No. of Years Education of Husband:

Estimated Annual Family Income: Under $\$ 10,000$
$\$ 10,000-\$ 15,000$
$\$ 15,000-\$ 20,000$

Spouse's Age:

Current Date:

Do you have the option to stay in this area for the next 5 yrs.? How long have you lived in this area?

I do not wish to participate.

Please do not contact me. I am willing to complete the anonymous questionnaire only. I am willing to complete the anonymous questionnaire and personal interview. 
Appendix $C_{l}$ "Request for Volunteers". Notice Published in Ft. Ord Red Cross Newsletter, "Variorum". 5 May 1976, Vol. 1, No. 8

\section{WHAT IS IT LIKE TO BE THIRTY?}

Major Will Wilson, assigned to the Psychology Service of Silas B. Hays Army Hospital, and his wife, Barbara, are looking into this interesting question. It is their belief that adults continue to go through "stages" and may not meet a level of real maturity until 28-32 years of age. They also see this time as critical in marriage and career satisfaction.

Will and Barbara Wilson are presently looking into the feelings held by the $32-35$ year old married male and his wife. In their study they are asking for volunteers in this age bracket to fill out some paper and pencil questionnaires. Time to complete the questionnaire takes about one hour and is done at home on your own time. The information which is confidential becomes anonymous and is not even shared with married partners. Military and civilian couples are both needed. If you wish to volunteer or wish more information, please contact either of the researchers at 242-7506 or $242-2348$. 
Appendix Ds Letter of Introduction to Military Academy
Graduates

I am in the process of doing some research on life satisfaction. I am looking for possible differences between those of us who move frequently (mobile-military), and those who have the option to stay in one area if they so desire.

The 28-32 year period has been recently reported in research as crisis-filled for many of us. I am wondering how the potential issues of the 30-year old gets resolved.

I have approached numerous people for the study--mostly friendship chains. The military mobile sample is complete. I now need help in reaching couples in which.

1) The male is $32-35$ years old;

2) Have a child (children);

3) Have the option to stay in their present location for the next five years.

As a USIM 163. I am looking to other USMAs for help. I would appreciate your participation if you fit the criterion. I will provide you with a completed copy of the study, if you are selected to participate.

Unless you live close to Ft. Ord, an interview will not be possible.

The study is also being completed as part of $\mathrm{Ph}, \mathrm{D}$ requirements from the University of Rhode Island. 
Appendix E, Structured Self-Report Battery Instruction Sheet

This package includes two complete sets of questionnaires-one for you and one for your spouse. Please complete them independently and return them when completed in the included addressed envelopes. It is important that a timetable be established and that the questionnaires be completed within a week. You should have your completed of the questionnaire in the mail by

Upon receipt of both of the questionnaires and if you agreed to be involved in the personal interview, you will be contacted by phone so that we can find the best time for the interview portion.

Our experience has indicated that an hour in the afternoon with the wife and an hour in the evening with the husband works out best, but if you have another preference please let us know when we call. The interviews will be conducted by a same sexed interviewer.

The material that we collect will not be identified with your name, nor do we intend to provide one spouse with information given to us by the other partner. We believe that these "rules" are important for the conduct of this project.

Please contact us if any unusual difficulties arise.

Barbara \& will Wilson

Phones 242-2348 
Appendix F, Personal Data Collection Sheet

THIS ADDITIONAI DATA IS REQUIRED TO COMPARE SAMPLE GROUPS

(Please check one response for each question.)

1) Do you own a house? Yes___ No

2) How many years of education has been completed by: Yourself 12 years (high school)

13 years

14 years (2 yrs. jr. college)

15 years

16 years (college)

17 years (graduate studies)

18 years

19 years

20 years

Wife $\quad 12$ years (high school)

13 years

14 years $(2$ yrs. jr. college)

15 years

16 years (college)

17 years (graduate studies)

18 years

19 years

20 years

3) Do your children attend school? Yes No If yes, what type?
A) Public school
B) Private school
C) Military post school

4) About how much money do you and your wife expect to earn this year?

5) What are the ages of your children at this time? 
Appendix Gs Male Interview Question Format

1) Short Questionnaire (Areas of Satisfaction Rating Scale)

2) I'd like to ask some questions about each of these areas

3) In terms of life satisfaction. I see that you rate it as (From \#1). Could you tell me what are some of the most satisfying aspects of your life?

What are some of the least?

4) We tried to make a distinction between job (those things that you are presently doing) and career (your life's work).

5) You rated your job satisfaction (From \#1) . What are the areas that you find most satisfying about your job?

What are the least?

Is this job in line with your career?

6) You rated your career satisfaction as What are some of the most satisfying aspects of it?

What are some of the least?

7) Are you where you want to be in your career?

Is there anything holding you back? (If yes, what?)

Is there anything you can do about it?

What goal are you working towards your career?

8) Are these things outside of your career and family life that you would like to be more involved in? (If yes, what keeps you from doing it?)

9) How do you feel about spending your free time away from your family?

Do you and your wife get away by yourselves without your children overnight?

10) Would you leave your present career if the day-to-day routine was dissatisfying? (If yes, what things would make changing careers difficult?)

11) Give marriage problem area check sheet 
12) Look at those areas of much concern. Which of these areas seems the most concerning?

13) Have we hit the areas of least satisfaction in:

Family

Marriage

Sex

14) What are the most satisfying aspects in these areas?

Family

Marriage

Sex

15) As you were growing up, you must have thought about what your life would be like. How does where you are now compare with the way you thought it would be?

16) How do you feel about the amount of time that your wife puts into activities outside of the house?

17) In terms of how you see yourself, what are your strengths? What are your weaknesses? In terms of how you see your wife, what are her strengths? What are her weaknesses?

18) Are there any other areas of life satisfaction that we should have asked about?

19) What impact, if any, do you think our research will have on your marriage? 
Appendix $\mathrm{H}$; Female Interview Question Format

A) Iife Satisfaction

1) What are some of the most satisfying aspects of your life now?

2) What are some of the least satisfying aspects of your iffe now?

B) Job Satisfaction

1) Define your job.

2) What are its most satisfying aspects?

3) What are its least satisfying aspects?

C) Career

1) Define your career.

2) What are its most satisfying aspects?

3) What are its least satisfying aspects?

4) Are you where you want to be right now in your life?

5) Do you have aspirations for a later career outside your family?

6) What is holding you back from having that career now?

7) Do you feel involved in your husband's career? In what ways?

8) Has your husband ever asked you for help in his career? How?

9) Do you feel free to pursue activities outside the home? Is there any guilt about this? How does your husband feel about it?

10) What is your degree?

11) Has your husband been away on a long tour? What was harder, the separation adjustment or the reunion ad jus tment? 
Appendix $\mathrm{H}$ (Cont'd.)

12) As we grow up, we have an idea about what our lives will be like. Is your life the way you thought it would be? How same? How not?

13) If you could have one wish now, what?

14) What is your biggest regret about your life?

15) What are your strengths?

16) What are your weaknesses?

17) What are your husband's strengths?

18) What are your husband's weaknesses?

19) If you have one regret about your life, what is it?

20) What is your greatest wish for your life right now? 
Appendix I \& Semantic Differential

You are being asked to think about your feelings concerning areas in your life and then to rate them along nineteen dimensions. The extremes of each dimension are identified as the ends of a seven-point scale. For each dimension, you should think about your feelings and indicate where along the dimension you think it best falls.

For example, if the dimension is

Heavy $\begin{array}{lllllllll}7 & 6 & 5 & 4 & 3 & 2 & 1 & \text { Light }\end{array}$

and you would characterize your feeling about yourself as being very light, you would circle number "l". If you feel you are very heavy, circle " $7 "$. If the feeling is average weight in your mind, circle "4". Please respond to each dimension.

The areas that you are asked to think about your feelings for and dimensions begin on the following page. 
Appendix I (Cont'd.)

Think about your feelings about yourself and rate them on this scale.

$\begin{array}{lllllllll}\text { Valuable } & 7 & 6 & 5 & 4 & 3 & 2 & 1 & \text { Worthless }\end{array}$

$\begin{array}{lllllllll}\text { Sad } & 7 & 6 & 5 & 4 & 3 & 2 & 1 & \text { Happy }\end{array}$

Large $\quad \begin{array}{llllllll}7 & 6 & 5 & 4 & 3 & 2 & 1 & \text { Small }\end{array}$

$\begin{array}{lllllllll}\text { Dull } & 7 & 6 & 5 & 4 & 3 & 2 & 1 & \text { Sharp }\end{array}$

$\begin{array}{lllllllll}\text { Active } & 7 & 6 & 5 & 4 & 3 & 2 & 1 & \text { Passive }\end{array}$

$\begin{array}{lllllllll}\text { Weak } & 7 & 6 & 5 & 4 & 3 & 2 & 1 & \text { Strong }\end{array}$

Tense $\quad \begin{array}{llllllll}7 & 6 & 5 & 4 & 3 & 2 & 1 & \text { Relaxed }\end{array}$

Pleasant $\begin{array}{lllllllll}7 & 6 & 5 & 4 & 3 & 2 & 1 & \text { Unpleasant }\end{array}$

$\begin{array}{lllllllll}\dot{B} a d & 7 & 6 & 5 & 4 & 3 & 2 & 1 & \text { Good }\end{array}$

$\begin{array}{lllllllll}\text { Likeable } & 7 & 6 & 5 & 4 & 3 & 2 & 1 & \text { Unlikeable }\end{array}$

$\begin{array}{lllllllll}\text { Heavy } & 7 & 6 & 5 & 4 & 3 & 2 & 1 & \text { Light }\end{array}$

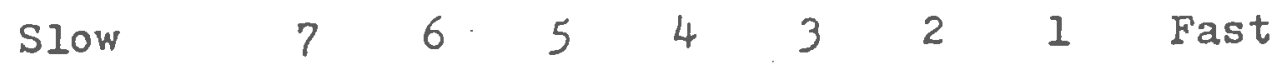

$\begin{array}{lllllllll}\text { Sincere } & 7 & 6 & 5 & 4 & 3 & 2 & 1 & \text { Insincere }\end{array}$

Dirty $\quad \begin{array}{llllllll}7 & 6 & 5 & 4 & 3 & 2 & 1 & \text { Clean }\end{array}$

Sweet $\quad \begin{array}{llllllll} & 6 & 5 & 4 & 3 & 2 & 1 & \text { Bitter }\end{array}$

$\begin{array}{lllllllll}\text { Cruel } & 7 & 6 & 5 & 4 & 3 & 2 & 1 & \text { Kind }\end{array}$

$\begin{array}{lllllllll}\text { Thick } & 7 & 6 & 5 & 4 & 3 & 2 & 1 & \text { Thin }\end{array}$

$\begin{array}{lllllllll}\text { Warm } & 7 & 6 & 5 & 4 & 3 & 2 & 1 & \text { Cool }\end{array}$

$\begin{array}{lllllllll}\text { Boring } & 7 & 6 & 5 & 4 & 3 & 2 & 1 & \text { Interesting }\end{array}$ 
0
o
0
0
3
0
0
0
0
0
$\frac{1}{10}$

त्त 0 व

i क्षे

म

पर नात

出

我

द 4

-

0

का मे

-

(d)

a

4 얻

ता

तो के

4 \&

4 क

म

×

नु 2 in

ब तु

م

व मि०
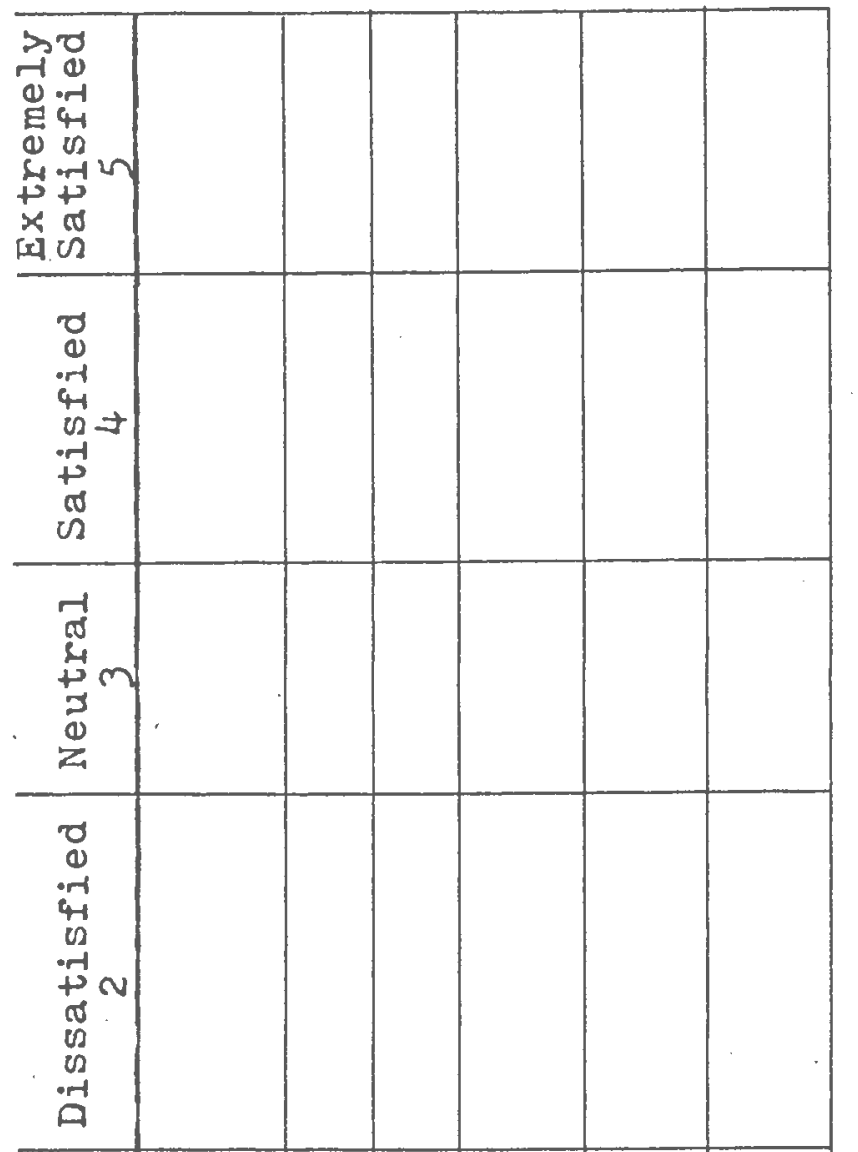

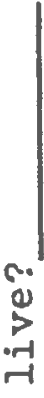

$+$

+
0
0
0
$x$
0
3
0
0

잉

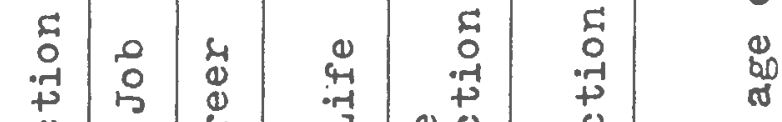

离

E 
Appendix $K$ : Life Evaluation Chart

On this page you are being asked to give an indication of your overall satisfaction with life, using the dimensions below. The left (vertical) axis represents the satisfaction level on a scale of 1 to 9 which you felt in the past, which you feel now, and which you anticipate feeling as long as you live. A rating of 1 would indicate that you feel extremely dissatisfied at that time in your life; a rating of 9 would indicate a feeling of extremely satisfied. The bottom axis indicates years of your lifetime.

Please follow these instructions.

1) Indicate your present age in the blank at the rights

2) Indicate your age when you started your present careers

3) What do you consider your present career to be?

4) Locate points along the graph indicating the satisfaction that you remember from the past, what you presently feel. and what you anticipate feeling as long as you expect to live.

5) Connect the points of your graph with a line.

Satisfaction Level

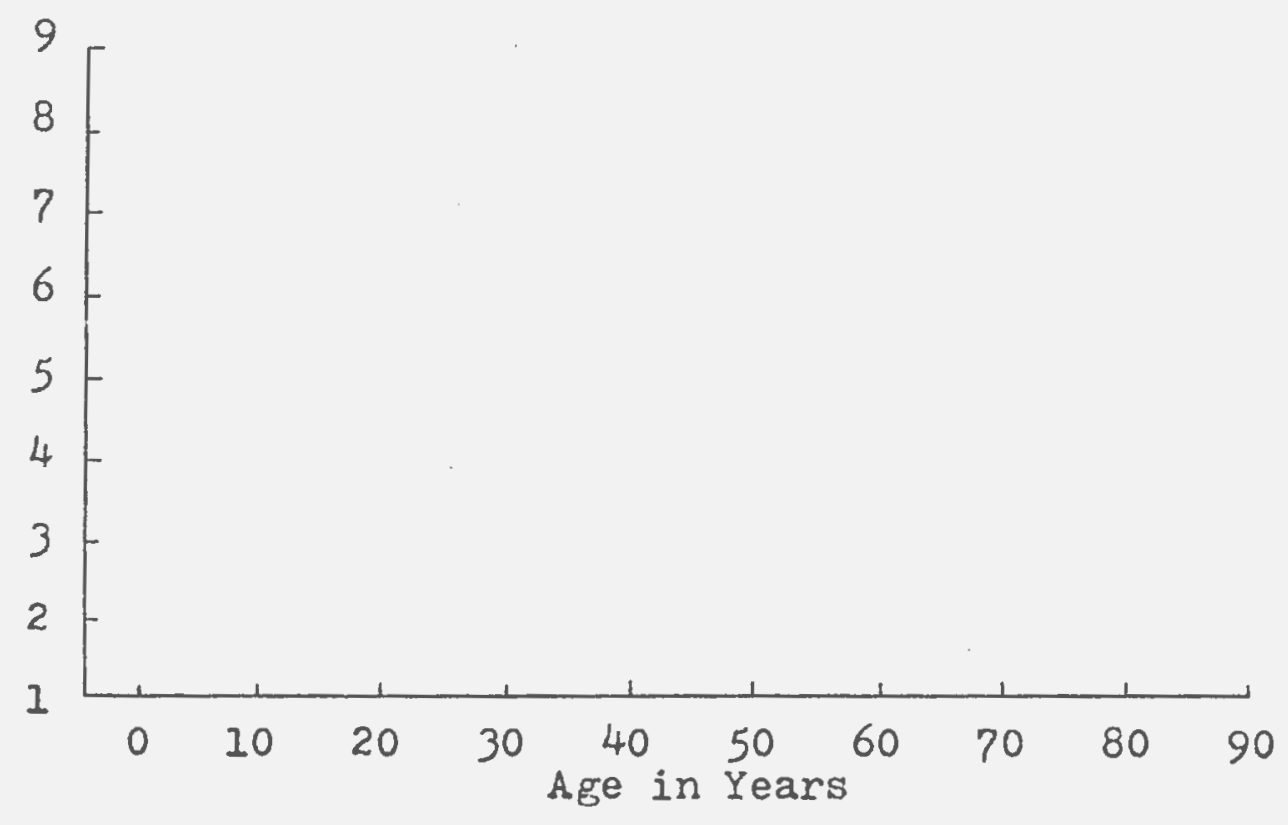


Appendix L, Marriage Evaluation Chart

On this page you are being asked to construct a graph similar to the one that you completed on the previous page. The difference is that this graph is concerned only with your marital satisfaction. Again, the vertical axis reprepresents your level of satisfaction on a scale of 1 (extremely dissatisfied with your marriage) to 9 (extremely satisfied with your marriage). The bottom axis represents years of your life.

Please follow these instructions.

1) Indicate your present age:

2) Indicate your age on the date of your present marriage:

3) Number of previous marriages:

4) Your age at the birth(s) of your childrens

5) Locate points and connect them with a line as you did in the previous graph in terms of the marital satisfaction that you remember from the past, experience now, and expect in the future.

Satisfaction Level

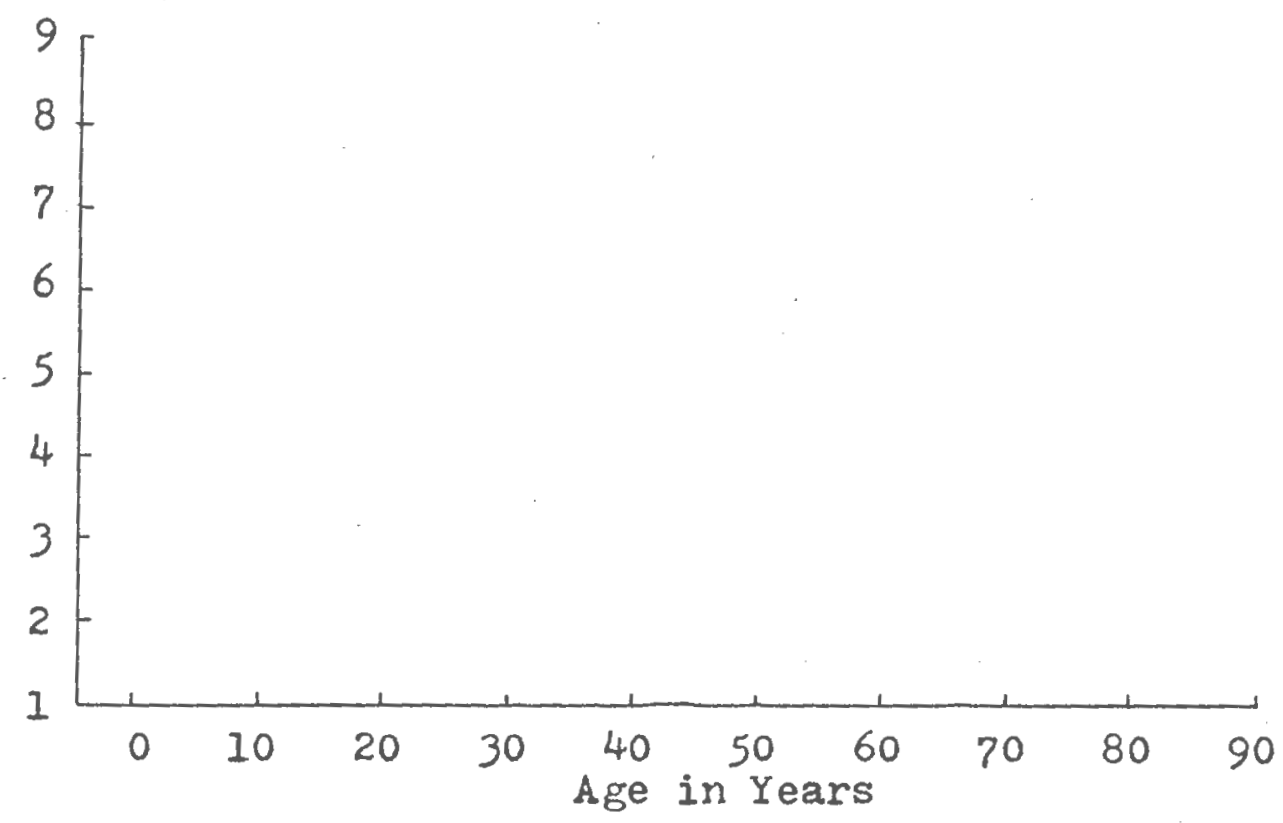

MARITAL SATISFACTION 
Appendix M: Marriage Problem Area Checklist

The items on this questionnaire refer to possible problem areas in your marriage. For each question, please check the column that describes how much you are concerned about it at present.

A) COMUUUNICATION

1. Too little time spent in communicating

2. Nothing to talk about

3. Intellectual gaps

4. Topic or type of conversation (for example, one enjoys gossiping, the other talking about work)

5. How often to communicate. when apart

6. Bitching

7. Manner of communication. hasty or impatient

8. Others

B) SEX

1. When: AM, PM, before supper, etc.

2. Spouse too crude in approach

3. Too little foreplay

4. Frequency

5. Premature ejaculation

6. Frigidity

7. Infidelity

8. Sex information

10. Impotence

11. Others

c) MONEY

1. Amount

2 . Source of money

3. Who spends

4. How much is spent 
Appendix M (Cont'd.)

5. How it is spent

6. Who manages the money

2. Others

D) In-LAWS

1. Which ones to go visit

2. How much time is spent with parents or in-laws

3. In-laws show dislike for daughter/son-in-law

4. In-laws meddle and try to run children's lives

5. Whether to help in-laws financially

6. Advice from

7. Mate hates partner's parents

8. In-laws do not like each other

2. Others

E) RELIGION

1. Different religions

2. Religion for children

3. One spouse more devout than the other

4. Manner of celebrating holidays

5. Disagreement over religious rituals

(for example, birth control or

circumcision)

6. Shoney to church

7. Unkept vows

8. Others

F) RECREATION

1. Amount of time for specific recreative activities

2. How time will be spent

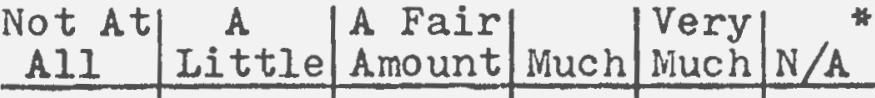


Appendix $M$ (Cont'd.)

3. With whom the time will be spent (solitary vs. family recreation)

4. When to enjoy recreation (for example, after work or before, on Sunday morning or Saturday)

5. Where to spend vacation

6 . Competition ffor example, "egos" may be hurt if wife is more athletic than husband)

G) FRIENDS

1. Different friends

2. Time with

3. Confidences to friends

4. Too few friends

5. Too many friends

5. Others

H) AICOHOL

1. Who drinks

2. How much alcohol is acceptable

3. When and where to drink

4. Amount of money spent on alcohol

5. What to teach children about alcohol

6. Certain friends or relatives disapprove of your drinking

7. Different brands ffor example, disagree on the merit of each)

8. Flirting because of drinking or general embarrassment or violence

9. Others

\begin{tabular}{l|c|cc} 
Not At & A & A Fair & Very \\
All & Little & Amount & Much Much
\end{tabular} \mid $\mathrm{N} / \mathrm{A}^{*}$


Appendix $M$ (Cont'd.)

I) CHILDREN

1. Number

2. Spacing

3. Discipline

4. Time with

5. Activities child should become involved in

6. Rivalry for children's love

7. Whether to adopt

8. Retarded or malformed or unwanted child

2. Step-chilaren

10. Sex education

11. Others

* Not applicable

Copyright 1971 by Family Life Publications, Inc. 


\section{REFERENCES}

Bachman, J., Kahn, R., Davidson, T. and Johnson, L.

Youth in Transition--Volume 1. Ann Arbor, Michigan:

Institute for Social Research, 1967.

Bernard, Jessie. The Future of Marriage. New York:

Bantam Books, 1972 .

Birdwhistell, Ray L. Kinesics and Context. Philadelphia:

University of Pennsylvania Press, 1970.

Blood, R. O. and Wolfe, D. M. Husbands and Wives: The

Dynamics of Married Living. New York: Free Press, 1960.

Bradburn, N. M. The Structure of Psychological Well Being.

Chicago: Aldine, 1969.

Campbell, A. The American way of mating, marriage si,

children only maybe. Psychology Today. May 1975.

Campbel1, J. The Portable Jung. New York: Viking, 1971.

Converse, $\mathrm{P}$. and Robinson, $\mathrm{J}$. The Use of Time in American

society, in press.

Dobrofsky, Lynne $R$. and Batterson, Constance. The

military wife and feminism. Signs, Journal of Women in Culture and Society, $1977,2(3), 675-684$.

Erickson, E. H. Childhood and Society. New York: Norton, 1968.

Fengler, A. P. The effects of age and education on marital ideology. Journal of Marriage and the Family, 1973, $35,264-271$. 
Garai, J. E. Sex differences in mental health. Genetic Psychology Monographs, 1970, 81, 123-143. Gould, Roger. The phases of adult life: a study in developmental psychology. American Journal of Psychiatry, 1972, 129(5), 33-43. - Adult life stages, growth towards selftolerance. Psychology Today, 1975, 74-78.

Gurin, G., Veroff, J., and Feld, S. Americans View Their Miental Health. New York: Basic Books, 1960. Harry, Joseph. Evolving sources of happiness for men over the life cycle: a structural analysis. Journal of Marriage and the Family, 1976, 38(2), 289-296. Hawkins, James L. and Johnson, Kathryn. Perception of behavioral conformity, imputation of consensus, and marital satisfaction. Journal of Marriage and the Family, 1969, 31, 507-511.

Heise, D. R. Methodology of the semantic differential. Psychologia Bulletin, 1969, 72, 406-422.

- The semantic differential in attitude research.

In G. Summers (ed.) Attitude Measurement. Chicago: Rand McNally, 1970.

Herzberg, Frederick. Work and the Nature of Man. New York: New American Library, 1966. Hicks, Mary $w$. and Platt, Marilyn. Marital happiness and stability: a review of the research in the sixties. Journal of Marriage and the Family, 1970, 32, 553-574. 
Hollingshead, August de Belmont and Redlich, Frederick.

Social Class and Mental Illness: A Community study.

New York: Wiley, 1958.

Jenkins, J. J., Russell, W. A. and Suci, G. J. An atlas

of semantic profiles for 360 words. American Journal

of Psychology, 1958, 71, 688-699.

Jourard, S. M. The Transparent Self. Princeton, New Jersey:

D. Van Nostrand Co., 1964.

Jung, C. G. Modern Man in Search of a Soul. New York:

Harcourt, Brace, 1933, 95-114.

- The relations between the ego and the unconscious.

Collected Works, Vol. 7. Princeton, New Jersey:

Princeton University Press, 1953, 121-304.

Just, Ward. Soldiers. Atlantic Magazine, 1970, October,

58-89, November, 59-90.

Knapp, R. R. Relationships of a measure of self-

actualization to neuroticism and extraversion.

Journal of Consulting Psychology, 1965, 29, 168-172.

Ladycom Survey Results. Ladycom, October 1977, pp. 14-16, $25,28,36$.

Lemon, Nigel. Attitudes and Their Measurement. New York: wiley, 1966.

Levinger, George. Sources of marital dissatisfaction among applicants for divorce. American Journal of Orthopsychiatry, $1966,36,803-807$.

Levinson, D. J., Darrow, C. M., Klein, E. B., Levinson, M. H. and McKee, B. The psychosocial development 
of men in early childhood and the mid-life transition. In Ricks, D. F., Thomas, A., and Roff, M. (eds.) Iife History Research in Psychopathology: III. Minneapolis: University of Minnesota Press, 1974. Lowenthal, Marjorie F., Thurner, Majda and Chiriboga, David. Four Stages of Life. San Francisco: JosseyBass, 1975.

Luckey, Eleanore B. Marital satisfaction and its association with congruence of perception. Marriage and Eamily Living, 1960a, 22(1), 49-54. - Marital satisfaction and parent concepts. Journal of Consulting Psychology, 1960b, 24, 195-204. - Perceptual congruence of self and family

concepts as related to marital interaction.

Sociometry, 1960c, 24(9), 234-250.

Maslow, Abraham 1 . Toward a Psychology of Being. New York: Van Nostrand, 1968.

Mckain, Jerry L. Relocation in the military: alienation and family problems. Journal of Marriage and the Family, 1973, 35(4), 205-209.

Orden, Susan R. and Bradburn, Norman M. Dimensions of happiness in marriage. American Journal of Sociology, $1968,73(3), 715-731$.

Ort, Robert $S$. Some implications of the class concept for clinical psychology. Psychological Service center Journal, 1950, 3, 189-197. 
Osgood, Charles E., Suci, George J. and Tannenbaum,

Percy N. The Measurement of Meaning. Urbana:

University of Illinois Press, 1957.

Pineo, P. C. Disenchantment in the later years of marriage.

In Neugarten, B. L. (ed.) Middle Age and Aqing.

Chicago: University of Chicago Press, 1968.

Robinson, J. Occupational norms and differences in job satisfaction. In Robinson, J., Athanasiov, R. and Head, K. Measures of Occupational Attitudes and Occupational Characteristics. Ann Arbor: Survey Research Center, Institute for Social Research, 1969. - Life satisfaction and happiness. In Robinson,

J. and Shaver, P. R. Measures of Social Psychological Attitudes. Ann Arbor: Survey Research Center, Institute for Social Research, 1974.

Rollins, Boyd $C$. and Feldman, Harold. Marital satisfaction over the family life cycle. Journal of Marriage and the Family, 1970, 32(1), 20-27.

Sarason, S. B., Sarason, E. K. and Cowden, P. Aging and the nature of work. American Psychologist, 1975. Vol. 30,5 .

Sheehy, G. Catch-30 and other predictable crises of growing up adult. New York Magazine. New York: New York Times Publishing Company, Inc., 18 February 1974. - Passages, Predictable Crises of Adult Development. New York: E. P. Dutton and Company, Inc., 1976. 
Shostrom, E. L. A test for the measurement of selfactualization. Educational and Psychological Measurement, 1964, 24, 207-218.

- Manual For the Personal Orientation Inventory.

San Diego: Educational and Industrial Testing Service, 1966.

and Knapp, R. R. The relationship of a measure of self-actualization (POI) to a measure of pathology (MMPI) and to therapeutic growth. American Journal of Psychotherapy, 1966, 20, 193-202.

Warr, P. B. and Knapper, C. The Perception of People and Events. London: Wiley, 1968.

Wilensky, H. I.' Life cycle, work situations, and participation in formal associations. In Kleemeier, R. (ed.) Aging and Leisure. New York: Oxford, 1961. Wills, Thomas A., Weiss, Robert L, and Patterson, Gerard R. A behavioral analysis of the determinants of marital satisfaction. Journal of Consulting and Clinical Psychology, 1974, 42(6), 802-811. Wilson, W. Correlates of avowed happiness. Psychological Bulletin, 1967, 67, 294-306. Winer, B. J. Statistical Principles in Experimental Design. New York: McGraw-Hill, 1971. 